\title{
Analysis of Stress Corrosion Cracking in Alloy 718 Following Commercial Reactor Exposure ${ }^{\dagger}$
}

\author{
Keith J. Leonard $^{1 *}$, Maxim N. Gussev ${ }^{1}$, Jacqueline Stevens ${ }^{2}$, Jeremy T. Busby ${ }^{1}$ \\ ${ }^{1}$ Oak Ridge National Laboratory, Oak Ridge, Tennessee, USA \\ ${ }^{2}$ AREVA Inc., Lynchburg, Virginia, USA
}

\begin{abstract}
Alloy 718 is generally considered a highly corrosion-resistant material but can still be susceptible to stress corrosion cracking (SCC). The combination of factors leading to SCC susceptibility in the alloy is not always clear enough. In the present work, alloy 718 leaf spring (LS) materials that suffered stress corrosion damage during two 24-month cycles in pressurized water reactor service, operated to $>45 \mathrm{MWd} / \mathrm{mtU}$ burn-up, was investigated. Compared to archival samples fabricated through the same processing conditions, little microstructural and property changes occurred in the material with in-service irradiation, contrary to high dose rate laboratory-based experiments reported in literature. Though the lack of delta phase formation along grain boundaries would suggest a more SCC resistant microstructure, grain boundary cracking in the material was extensive. Crack propagation routes were explored through focused ion beam milling of specimens near the crack tip for transmission electron microscopy as well as in polished plan view and cross-sectional samples for electron backscatter diffraction analysis. It has been shown in this study that cracks propagated mainly along random high-angle grain boundaries, with the material around cracks displaying a high local density of dislocations. The slip lines were produced through the local deformation of the leaf spring material above their yield strength. The cause for local SCC appears to be related to oxidation of both slip lines and grain boundaries, which under the high in-service stresses resulted in crack development in the material.
\end{abstract}

Keywords: Alloy 718, Post-irradiation Examination, Stress Corrosion Cracking

Corresponding Author:

Keith J. Leonard

Materials Science and Technology Division

Oak Ridge National Laboratory

P.O. Box 2008, MS-6138

Oak Ridge, TN 37831-6138

phone (865) 576-3687

fax (865) 241-3650

leonardk@ornl.gov

$\dagger^{\top}$ This manuscript has been authored by UT-Battelle, LLC, under Contract No. DE-AC05-00OR22725 with the U.S. Department of Energy. The United States Government retains and the publisher, by accepting the article for publication, acknowledges that the United States Government retains a non-exclusive, paid-up, irrevocable, world-wide license to publish or reproduce the published form of this manuscript, or allow others to do so, for United States Government purposes. The Department of Energy will provide public access to these results of federally sponsored research in accordance with the DOE Public Access Plan (http://energy.gov/downloads/doe-public-access-plan). 


\section{Introduction}

The performance of Ni-base alloy 718 in light water reactor systems is dependent on many factors that include the starting microstructure and its subsequent evolution under the combination of applied stresses, irradiation and corrosive environments. While generally considered resistant to primary-water stress corrosion crack (SCC) initiation, alloy 718 can be susceptible to crack propagation. The starting microstructure of the material and the changes it undergoes are directly linked to the mechanical strength and corrosion properties of the component and influence the susceptibility of the material to crack propagation mechanisms leading to degraded function or failure of components. While Alloy 718 is used in numerous significant nuclear and nonnuclear applications, the crack propagation behavior and conditions that promote SCC in alloy 718 are not as well studied as those of other alloys, such as austenitic steels. This is specifically the case for material that has shown failure during reactor exposure.

Damaged cruciform-type hold-down leaf spring (LS) arms were observed during refueling outage inspections at several pressurized water reactors (PWRs) between 2007 and 2009. Two sets of LS assemblies from a US PWR reactor were harvested from the upper end fitting of the fuel assembly after two 24-month cycles in the reactor operated to $>45 \mathrm{MWd} / \mathrm{mtU}$ burn-up. The assemblies were shipped to the Irradiated Materials Examination and Testing hot cell facility at Oak Ridge National Laboratory (ORNL) for inspection and disassembly and to be cut into test materials. Further in-depth studies on smaller components cut from select sections of the leaf spring assemblies were performed at the ORNL Low Activation Materials Development and Analysis (LAMDA) laboratory.

In the post-irradiation examination work reported herein, we examine the crack propagation characteristics and statistical analysis as related to the route of propagation. Evaluation of potential crack nucleation sites and characterization of the cracks were also performed through transmission electron microscopy (TEM) and is discussed with general microstructural and hardness property differences between the irradiated and nonirradiated (archived) samples available from the same fabrication processing batch of material.

\section{Material and Experimental Methods}

The alloy 718 spring material is cold rolled, machined, solution annealed and precipitate hardened through heat treatments in accordance with the Aerospace Materials Specification 5596 [1] and LS vendor's internal proprietary specifications. The alloy composition is listed in Table 1.

For the $\sim 45 \mathrm{MWd} / \mathrm{mtU}$ burn-up that the LS assemblies received during the two 24-month cycles in PWR service, the irradiated material presented in this study received a dose of $9 \times 10^{23} \mathrm{n} / \mathrm{m}^{2}$ $(\mathrm{E}>1 \mathrm{MeV})$. Equivalent displacement damage based on experimental reactor conditions assuming a primary influence of fast neutrons would produce approximately 0.14 displacements per atom (dpa) [2]. Taking into account thermal and epi-thermal neutrons, the effective damage level could be a little higher due to displacement damage generated through $\mathrm{Ni}^{59}(n, \alpha) \mathrm{Fe}^{59}$ reactions [3]. He generation is not considered to be substantial due to the low total thermal fluence and B content within the alloy. Irradiation temperature during reactor service was nominally $317^{\circ} \mathrm{C}$.

Analysis of cracked features and polished metallographic samples was conducted using a Keyence VHX-1000 digital confocal microscope with image stitching capability, allowing for the large-area investigations. Vickers microhardness data (500 g load, $10 \mathrm{~s}$ dwell time) was collected 
on either etched or electropolished surfaces of prepared metallographic samples. Tests performed on archival materials in the polished and etched conditions revealed no statistical difference.

Table 1. Elemental composition of the material investigated (in wt \%).

\begin{tabular}{|c|c|c|c|c|c|c|c|c|c|c|c|}
\hline $\mathrm{Ni}$ & $\mathrm{Cr}$ & $\mathrm{Fe}$ & $\mathrm{Nb}$ & Mo & $\mathrm{Ti}$ & $\mathrm{Al}$ & $\mathrm{Si}$ & $\mathrm{Mn}$ & $\mathrm{C}$ & $\mathrm{Co}, \mathrm{Ta}, \mathrm{Cu}$ & $\mathrm{P}, \mathrm{S}, \mathrm{B}$ \\
\hline Bal. & 17.9 & 18.0 & 4.93 & 2.95 & 1.05 & 0.44 & 0.07 & 0.08 & 0.028 & $<0.008$ & $<0.002$ \\
\hline
\end{tabular}

Electron-backscatter diffraction analysis (EBSD) was performed using a field emission JEOL JSM 6500F scanning electron microscope (SEM) equipped with an orientation imaging microscopy (OIM) system by EDAX. For EBSD work, the SEM accelerating voltage was $20 \mathrm{kV}$; the working distance varied from 12 to $15 \mathrm{~mm}$. The EBSD maps were measured on a hexagonal grid with a step size of 0.1 to $2 \mu \mathrm{m}$. Each of the beam-scan fields was measured at a magnification of $5000 \times$ or more to ensure that all points were in focus.

All EBSD data were filtered (minimum grain size three points, maximum point-to-point misorientation $5^{\circ}$ ) to reduce indexation errors. Image quality (IQ) maps were drawn to obtain qualitative information about the microstructure of the deformed samples. The IQ maps describe the quality of the electron backscatter patterns, which is related to the strain distribution in the microstructure [4] as well as reveal details such as grains, twins, phase boundaries, cracks, and slip bands.

Samples for TEM were prepared either through conventional twin-jet electropolishing of $3 \mathrm{~mm}$ discs from the archive material, or through focus ion beam (FIB) milling of the irradiated material. Jet-polished samples were prepared using a Struers Tenupol polisher with an electrolyte of 10 vol $\% \mathrm{HClO}_{4}$ in methanol, at temperatures between -20 to $-30^{\circ} \mathrm{C}$ and $\sim 20 \mathrm{~V}$. Specimens for TEM from the irradiated material were prepared by FIB milling using an FEI Quanta 3D 200i instrument at site-selective locations, which included lift-out samples from the cracked regions and representative lift-outs from the bulk material away from the cracks. Samples were examined on an FEI CM200 TEM, a Schottky $200 \mathrm{keV}$ field emission instrument with scanning-TEM (STEM) capabilities and equipped with an energy-dispersive spectrometer (EDS), a high-angle annular dark-field (HAADF) detector, and a Gatan image filter (GIF) for electron energy loss spectroscopy (EELS).

For the as-received specimens, the stress corrosion cracks at the surface were, in most cases, partially filled by corrosion products, restricting the view of the cracked surfaces and their analysis. A cleaning and etching procedure was employed to remove oxide layers and sediments and to get a clear metallic surface. The procedure used was as follows:

1. A 5 min soak at $\sim 100^{\circ} \mathrm{C}$ (boiling) solution of $30 \mathrm{~g} / \mathrm{L}$ potassium permanganate and $100 \mathrm{~g} / \mathrm{L}$ sodium hydroxide.

2. An additional $5 \mathrm{~min}$ soak in $\sim 100^{\circ} \mathrm{C}$ (boiling) solution of $30 \mathrm{~g} / \mathrm{L}$ ammonium oxalate.

3. Ultrasonic cleaning of the specimen in distilled water for up to $3 \mathrm{~min}$.

4. Repeating steps $1-3$ if found necessary.

The cleaning procedure was repeated up to six times to provide appropriate results; after cleaning, the oxide layer at the surface and the oxide within the near-surface cracks were fully removed. For comparison and control reasons, the same cleaning procedure was performed on an archive specimen of the same alloy (no corrosion layer). It was found that the control specimen did not 
reveal any change or damage to the surface in the form of etching, pitting, or overall material loss from the cleaning procedure, providing confidence that the structures revealed in the irradiated material following this procedure are an accurate representation of the in-service material.

\section{Results and Discussion}

\subsection{General Appearance of SCC in the Material Investigated}

Figure 1 provides examples of typical damage observed in the LS material. The optical images in this figure are composites of images taken across the width of the leaf arm at the location of maximum stress near the base of the arm located near the retaining nut (no cracking was observed at lower stress regions). Details regarding LS design and fabrication are proprietary. The level of in-service tensile stress at the cracked area, estimated using finite element analysis (FEA), was found to be $\sim 1000$ to $1200 \mathrm{MPa}$. It is difficult to provide more precise estimations because the stress level likely changed both during operation (fuel assembly growth) as cracks initiated and propagated.
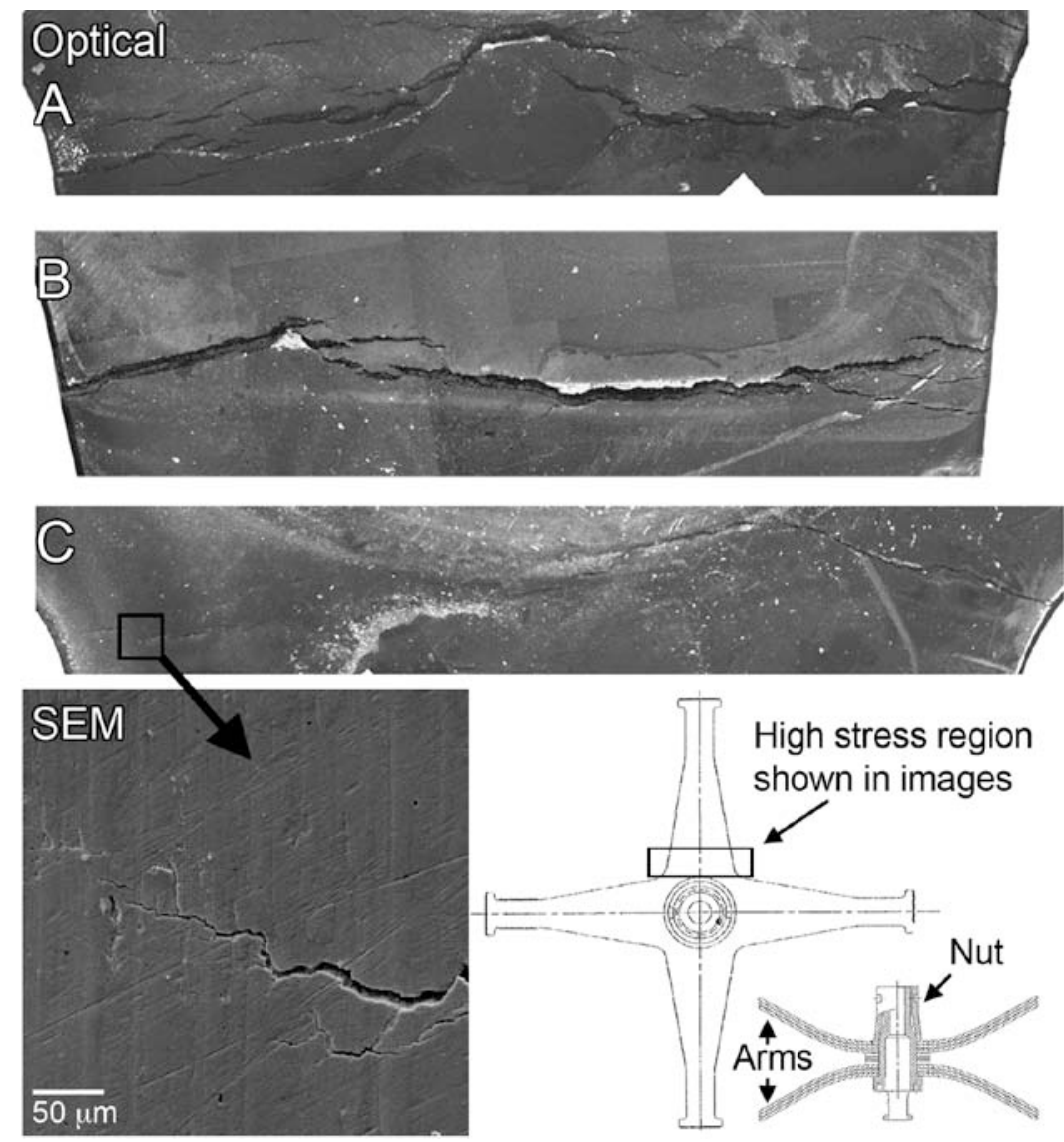

Figure 1. Example of the range in damage observed within the high-tensile-stress region of several leaf springs (LS) from one of the assemblies examined. The optical images are composites of multiple images taken across the width of the LS arm near its base. Images A-C were taken from different LS arms. Small cracks appearing in one of the leaf arms is further shown in the SEM image on the left. 
For the two LS assembly examples, approximately $20 \%$ of the leaf arms showed complete fractures (though some may have occurred during handling and shipping), 50\% showed cracking to a varying degree (with examples shown in Figure 1), and 30\% showed no crack formation. Optical examination and SEM revealed no specific defect, either microstructural (such as an inclusion) or created though fabrication of the springs that was directly linked to the nucleation of the crack. The cracks developed near the high-stress locations at the base of the arm and within the mid-span region, rather than at the edges. Much of the work reported here concentrates on the leaf arm showing limited cracking (example $C$ in Figure 1) to better evaluate the crack propagation routes and microstructural dependence.

\subsection{Radiation-Induced Microstructural and Hardness Changes}

General metallographic images of the microstructure of the alloy 718 LS material is shown in Figure 2, taken from a plan-view perspective (as opposed to a cross section). The average grain size was measured to be $12 \pm 2 \mu \mathrm{m}$ for the archive sample and $14 \pm 2 \mu \mathrm{m}$ in the irradiated material as measured from EBSD analysis (Table 2). Inclusions of (Nb,Ti)C identified through EDS analysis by SEM and TEM (results shown later) appear in groupings aligned relative to the rolling direction. While specific grain texturing was not observed in EBSD analysis due to the post-rolling annealing and precipitate treatments the material experienced, the directionality of the carbide particles persists. Grain morphology is generally equiaxed, with grains showing a high proportion of annealing twins. The grain size distribution was uniform, without any duplex or bimodal distribution, which could increase susceptibility for crack initiation [5].

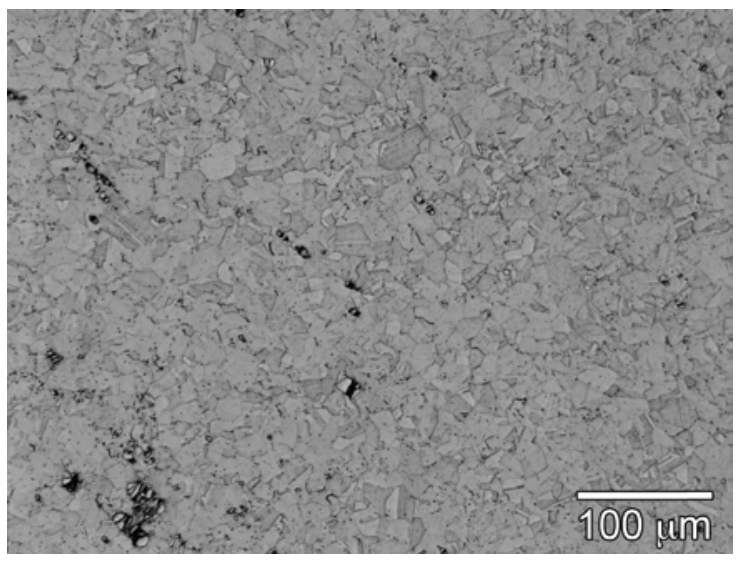

(a)

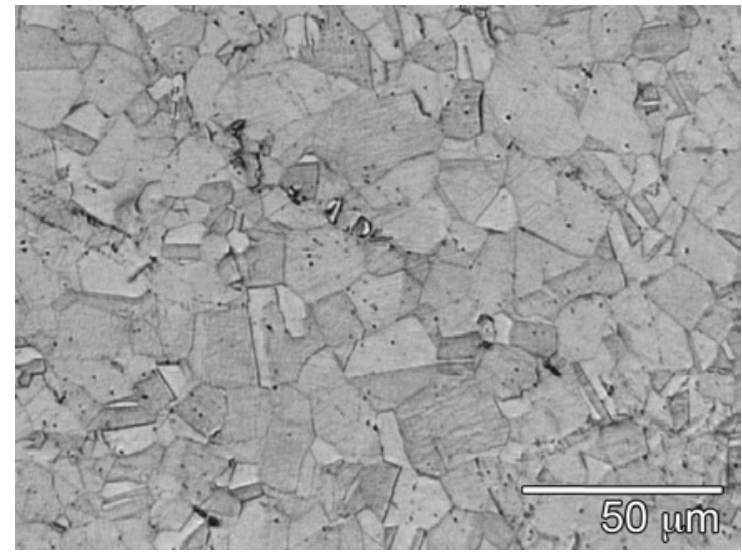

(b)

Figure 2. Optical images at two magnifications of the alloy 718 leaf spring microstructure. (a) The equiaxed grain structure is shown with annealing twins and inclusions aligned in the rolling direction. (b) Higher magnification image reveals further secondary precipitate particles in the microstructure.

A cross-section sample from the irradiated LS material shown as example C in Figure 1 was prepared through metallographic mounting and polishing. Due to the limited short crack length sections, it was believed that this particular leaf arm would reveal more information on the crack characteristics as compared to the more heavily damaged arms. Final polishing of the crosssection sample was performed using colloidal silica. The results showing the depth of penetration and branching of the cracks through the specimen thickness is presented in Figure 3. The three 
main cracks captured in the polished sample show a relatively direct propagation pathway through the high-tensile portion of the through thickness. This region extends to a depth of around $500 \mu \mathrm{m}$, below which significant crack branching occurs. In both regions, the crack pattern clearly follows along the grain boundaries. While the upper portion of the crack intersecting the tensile surface is driven open by the stresses associated in that region, it offers a short-circuit pathway for further oxidation of the grain boundaries of the grain interior. The midsection of the leaf is subjected to more conventional SCC branching-type patterns. The delay in crack branching to a significant depth into the material suggests that during operation the leaf form was subjected to high stresses.

Visible in the optical images of the cross section is the step height difference on either side of the crack at the tensile surface of the sample. This step change in vertical height was also observed in the SEM/FIB viewing of the surface. This indicates either a complex stress state or that the state of stress changed considerably on relief from the crack growth.

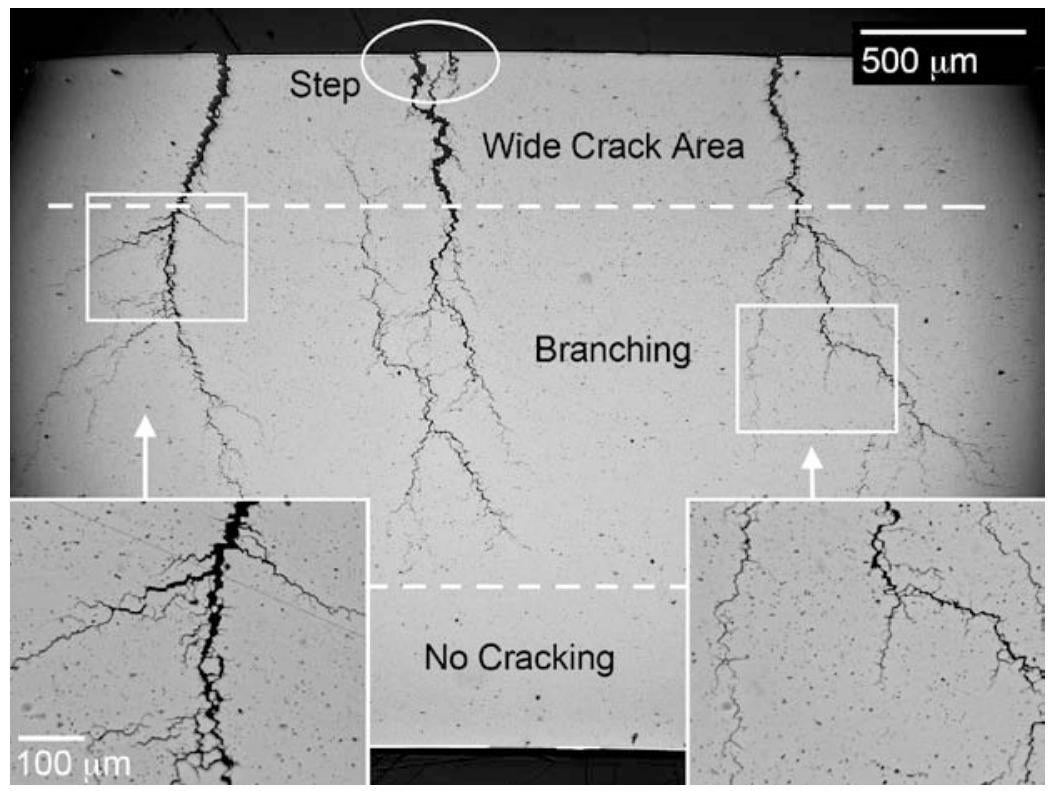

Figure 3. Low-magnification optical image of the polished cross section of C-sample (see Figure 1), with the wide cracks emanating from the tensile surface well into the thickness of the material before entering a region with significant branching. A step in the surface due to the crack is observed and is highlighted by the white oval. A slight curvature to the sample surfaces and the dark shading is due to optic distortion and the aperture visible at low magnification. The insets show two areas of the specimen at higher magnification.

Two microhardness profiles were taken across the polished through-thickness cross section of the irradiated LS and are shown in Figure 4. During loading, numerous slip lines formed around the indentation. Deformation relief was controlled by local grain configuration, and, according to EBSD, all analyzed slip lines corresponded to the surface traces of (111)-planes. In all cases, the material demonstrated ductile behavior; no crack formation was observed near the indentation, even at high load (500 g).

For the irradiated specimens, a number of measurements were conducted at different locations inside and outside the cracked area, near and far from cracks. It was established that the 
microhardness variations across the specimen thickness (Figure 4) were small, typical of the error in measurement $( \pm 5 \%)$, with no clear trend observed with no difference between the compressive and tensile surfaces of the LS. Differences in the microhardness values between the areas near cracks and away were also within the same measurement error.

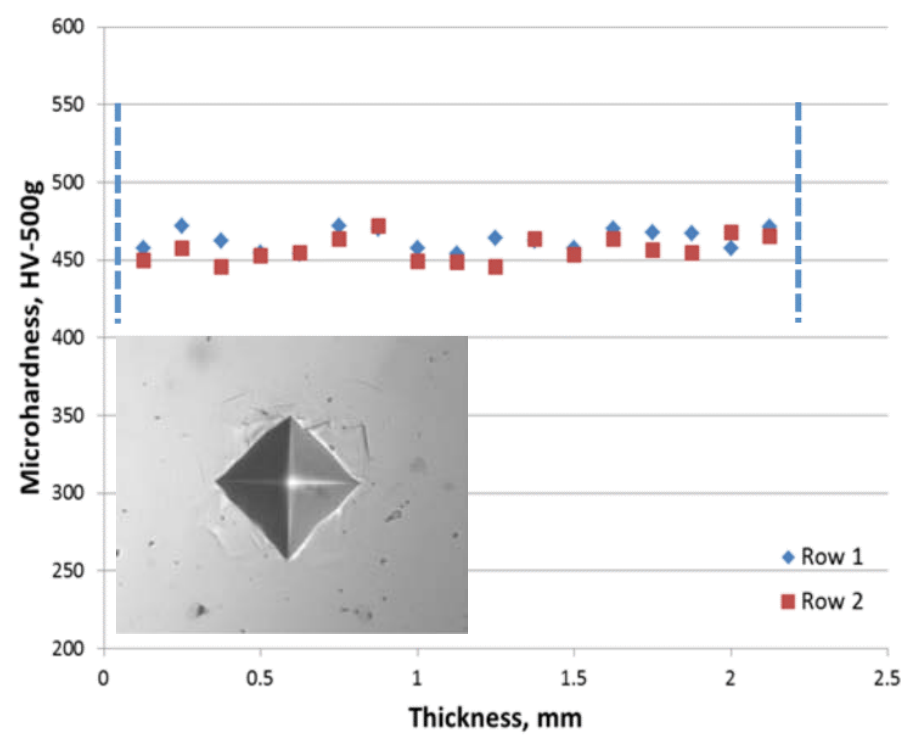

Figure 4. Cross-sectional hardness profiles from the tensile to compressive side of the spring. An insertion shows a typical Vickers indentation made on the cross-sectional surface of the irradiated spring material; note the plastically deformed regions on the surface.

The average microhardness value for the irradiated material (Table 2) was slightly lower compared with that of the archive material from the same heat. Vickers data obtained by Chen et al. for alloy 718 irradiated by $760 \mathrm{MeV}$ protons at a maximum temperature of $250^{\circ} \mathrm{C}$ [6] did not show significant downward trend in microhardness until about $3 \mathrm{dpa}$, but the data at the low irradiation doses were significantly scattered. However, the same samples did show a significant change in tensile properties [6], although damage values at low values for displacements per atom were not well represented.

Table 2. Microhardness (HV, kg/mm²) for $500 \mathrm{~g}$ load, and average grain size.

\begin{tabular}{|l|l|l|}
\hline Material & $\begin{array}{l}\text { Microhardness, } \\
500 \mathrm{~g}\end{array}$ & Grain size, $\mu \mathrm{m}^{*}$ \\
\hline Irradiated & 462 & $14 \pm 2$ \\
\hline Archive & 484 & $12 \pm 4$ \\
\hline $\begin{array}{l}\text { *Electron backscatter diffraction analysis data, high- } \\
\text { angle grain boundaries. }\end{array}$ \\
\hline
\end{tabular}

As will be shown in the TEM results, radiation-induced softening was very small, as was expected based on the relatively low accumulated dose despite being in service for four years. Radiation-induced softening of neutron-irradiated 718 was studied by Byun and Farrell [2]. Even at a relatively low damage dose range of 0.0006 to $1.2 \mathrm{dpa}$, the precipitation-hardened alloy 718 experiences some decrease in yield strength and a significant drop in ultimate tensile strength. The effect was explained by the influence of irradiation on precipitate structure. 
Sencer et al. [7] investigated 718 irradiated with a mixed spectrum of high-energy protons and spallation neutrons to the dose range of $\sim 0.1$ to $\sim 11 \mathrm{dpa}$. It was shown that tensile strength increased with damage dose below $\sim 0.5 \mathrm{dpa}$, and after that, it tended to decrease. The result was explained by the competition between radiation-induced hardening and softening due to the dissolution of precipitates. This was also consistent with decreases in hardness of protonirradiated materials above $0.1 \mathrm{dpa}$ at temperatures between room temperature to $400^{\circ} \mathrm{C}$ [8-10], in which changes to the precipitates in the material were observed through electron microscopy [10].

\subsection{Structure characterization of the leaf spring material via TEM}

The microstructure of the 718 alloy consists of equiaxed grains with a significant level of $\{111\}$ type twins, as shown in Figure 2. The material contains a uniform distribution of the precipitate $\gamma^{\prime}$ and $\gamma^{\prime \prime}$ phases. The $\gamma^{\prime}\left(\mathrm{L}_{2}, \operatorname{Pm} \overline{3} m\right.$ space group) precipitates are quasi-spherical in shape and formed coherently with the $\gamma$ solid solution phase with a nominal composition based on $\mathrm{Ni}_{3}(\mathrm{Ti}, \mathrm{Al})$, although with some minor alloying elements as well [11]. The $\gamma^{\prime \prime}\left(\mathrm{DO}_{22}, \mathrm{I} 4 / \mathrm{mmm}\right.$ space group) are disk-shaped metastable particles with compositions based on $\mathrm{Ni}_{3} \mathrm{Nb}$ with minor alloy concentrations. The $\gamma^{\prime}$ and $\gamma^{\prime \prime}$ precipitates show a distinct orientation relationship to the parent $\gamma$ phase of $\gamma<100>/ / \gamma^{\prime}<100>/ / \gamma^{\prime /}<010>, \gamma\{001\} / / \gamma^{\prime}\{001\} / / \gamma^{\prime /}\{001\}$.

The general microstructural features in the material investigated are discussed in this section. Details of the samples extracted near the cracks are discussed later in this paper. Examples of the archive material are shown in Figure 5, confirming the observations made under optical conditions. Only occasional $\delta$ - $\mathrm{Ni}_{3} \mathrm{Nb}$-type particles were observed within the grains and were few in number. The $\delta$ phase particles are likely formed during the high-temperature anneal as a result of local Nb-rich concentrations from the interdendritic segregation [12]. The grain boundaries of the archive materials were clean, with no evidence of a denuded zone. A comparison was made between the irradiated and archival material regarding changes in the $\gamma$ and $\gamma^{\prime \prime}$ phases following in-service exposure. Comparative select area diffraction (SAD) patterns along the $\gamma[100]$ zone axis directions using the same sample thickness (measured by Kossel-Möllenstedt fringe spacing) to equalize the kinematic diffraction conditions in each image as well as the same beam spread, aperture size, and camera exposure conditions are shown in Figure 6. Diffracted intensities of the $\gamma^{\prime}$ and $\gamma^{\prime \prime}$ phases producing the smaller reflections indexed in the images show little difference between the archive and irradiated material, with weaker higher-order reflections appearing in the irradiated sample. No evidence of precipitate disordering was observed in the irradiated material, which has been identified in previous irradiation studies of $\mathrm{L} 1_{2}$ strengthened alloys and is briefly reviewed by Zhang et al. [13]. The dark-field image of Figure 5 (d), in which reflections from both the $\gamma^{\prime}$ and $\gamma^{\prime \prime}$ phases are allowed to contribute to the image, shows these variants. While this method can be used to visually compare the precipitate size and distributions, it does not allow you to separate out contributions from each precipitate type due to the restrictions based on the size of the SAD aperture.

An imaging method that separates the reflections from the $\gamma^{\prime}$ and $\gamma^{\prime \prime}$ phases uses g-vector reflections off of the higher-index $\gamma$ [211] zone axis. The [211] zone axis is shown in Figure 7 for reference, and the comparative precipitate images of the archive and irradiated materials are shown in Figure 8. This method also allows the size difference between the $\gamma^{\prime}$ and $\gamma^{\prime \prime}$ precipitate phases to be illustrated, which cannot be distinguished in the dark-field image of Figure 5b due to the minimum aperture size creating the image. To improve imaging quality as well as prevent other diffracted beams from forming the image, the beam is tilted along the $g=\overline{2} 04$ type vector of the $\gamma$ phase off of the [211] zone to provide a two-beam image. From this condition, the beam 
can be adjusted to place the instrument into a dark-field condition for either the $\gamma^{\prime}$ or $\gamma^{\prime \prime}$ precipitates. As shown in Figure 7 , the $g=\overline{2} 04$ vector of the matrix also yields the $0 \overline{1} 1$ and $\overline{1} 02$ reflections of the $\gamma^{\prime}$ and $\gamma^{\prime \prime}$ phases, respectively. dark-field images (as shown in Figure 8) are produced by using the precipitate reflections to form an image. While the $\gamma^{\prime} \mathrm{g}=\overline{1} 02$ reflection also corresponds to the $\gamma^{\prime \prime} \mathrm{g}=0 \overline{2} 2$ reflection, this is a weaker $+2 \mathrm{~g}$ condition. Therefore, the darkfield images of the $\gamma^{\prime}$ phase also contain faint highlights of the $\gamma^{\prime \prime}$ phase. However, the fainter $\gamma^{\prime \prime}$ particles do not overwhelm the imaging of $\gamma^{\prime}$.

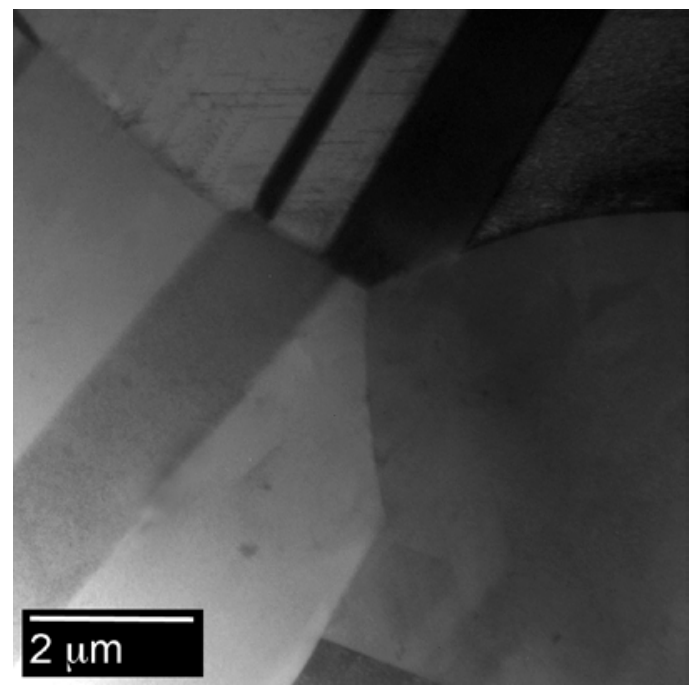

(a)

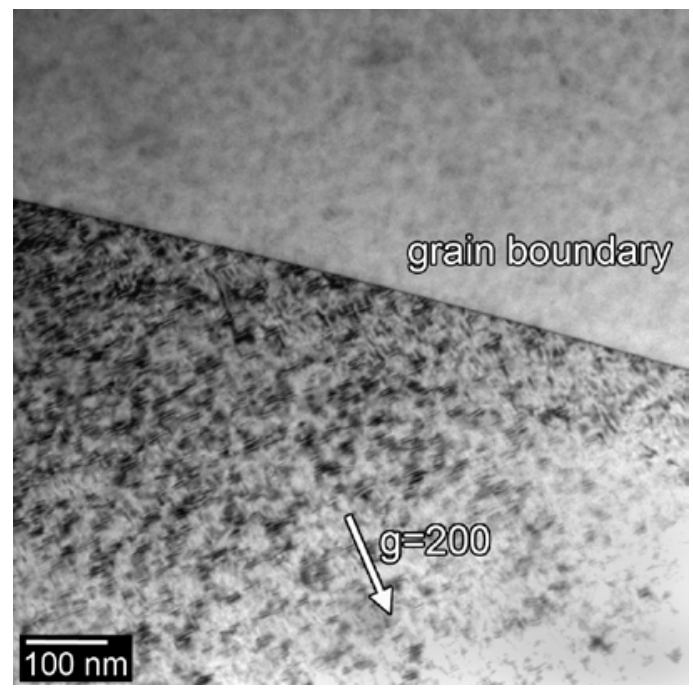

(c)

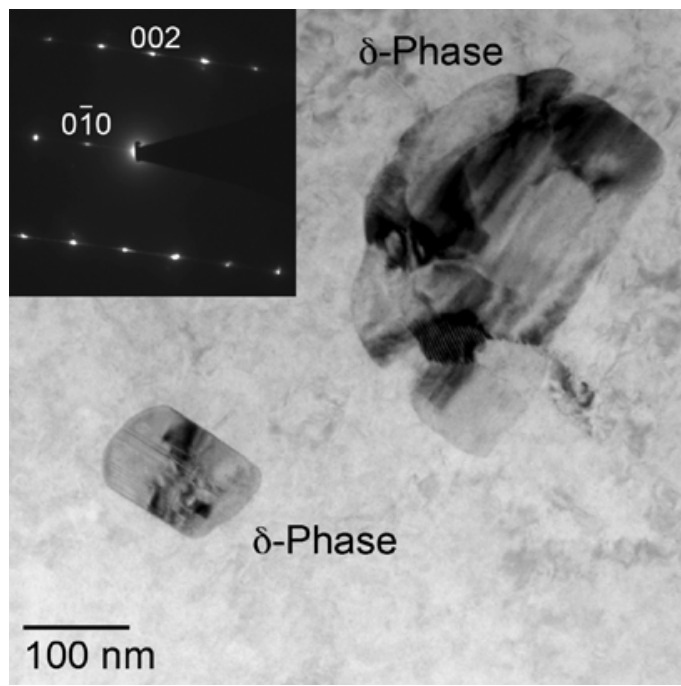

(b)

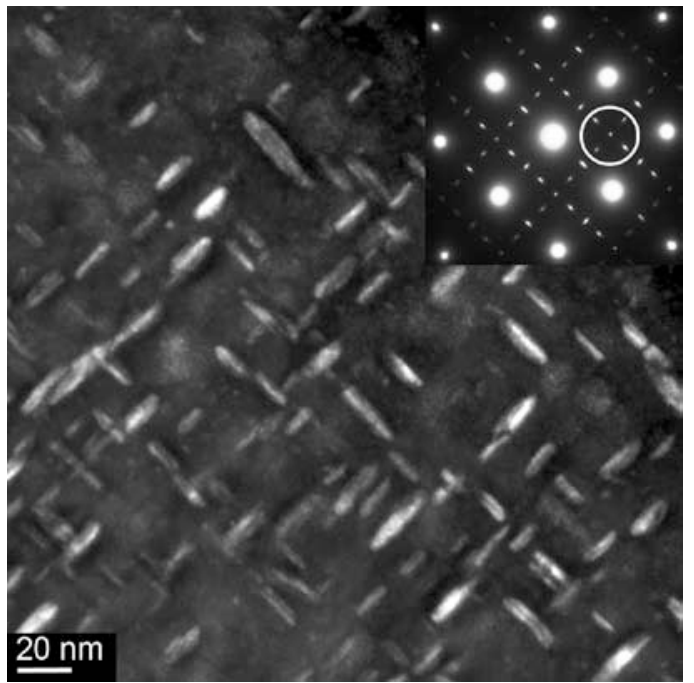

(d)

Figure 5. Transmission electron micrographs of the archive material showing (a) the general microstructure of equiaxed grains with twinning, with (b) widely dispersed groups of intragranular $\delta$ phase particles, inset showing the $\delta[100]$ pattern. (c) A typical example of a high-angle grain boundary showing no $\delta$ precipitation or denuded zone, and (d) dark-field image of the $\gamma^{\prime}$ and $\gamma^{\prime \prime}$ precipitate phases. Inset in (d) is of the $\gamma[100]$ zone axis showing position of the SAD aperture (white circle) used in the micrograph. 


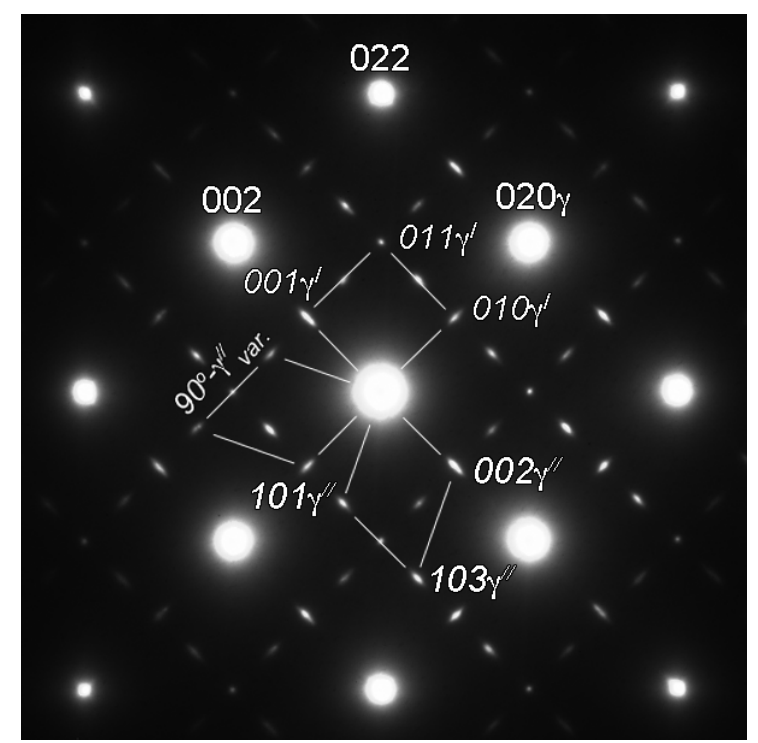

(a)



(b)

Figure 6. Select area diffraction patterns of the $\gamma[100]$ zone axis patterns of the (a) archive and (b) irradiated material, using the same transmission electron microscope settings, sample thickness, and camera exposure conditions. The $\gamma[100]$ reflections show two variants of the $\gamma^{\prime}$ and $\gamma^{\prime \prime}$ phases, with the $\gamma^{\prime}$ variants being coincident.

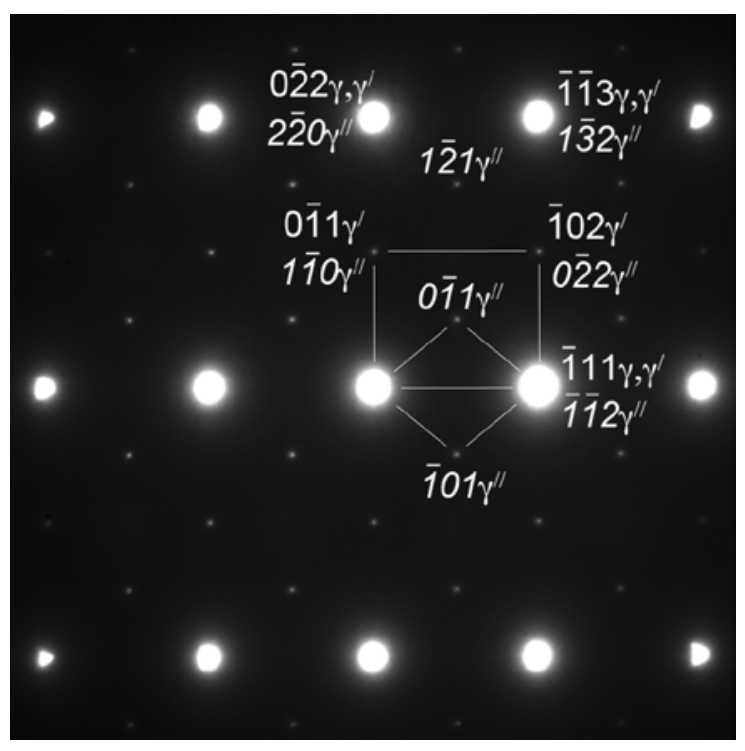

Figure 7. The $\gamma$ [211] pattern indexed showing the $\gamma, \gamma^{\prime}$, and $\gamma^{\prime \prime}$ reflections. Dark-field images off the $g=\overline{2} 04$ type of vector can be used to separate the reflection contributions from the $\gamma^{\prime}$ and $\gamma^{\prime /}$ phases. 


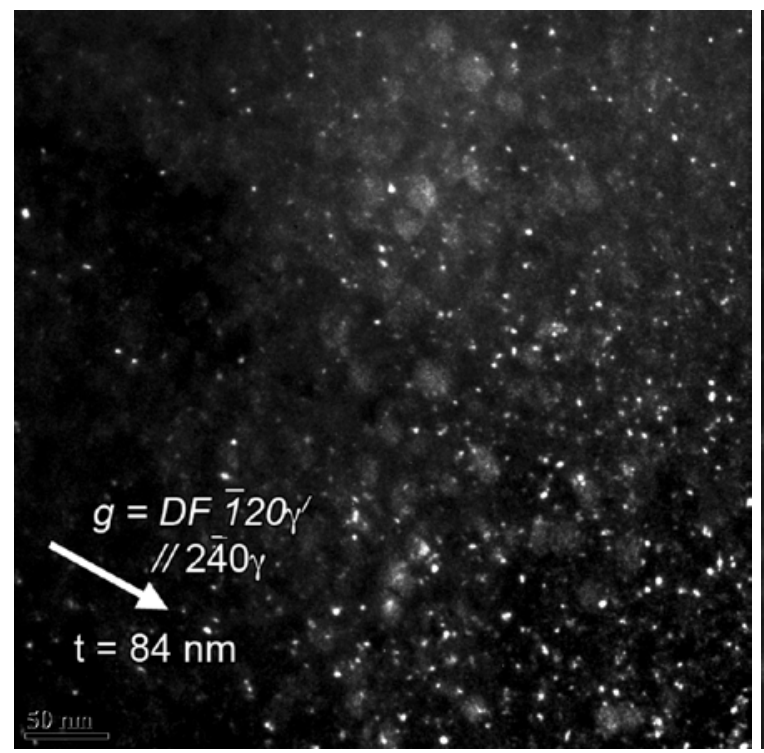

(a)

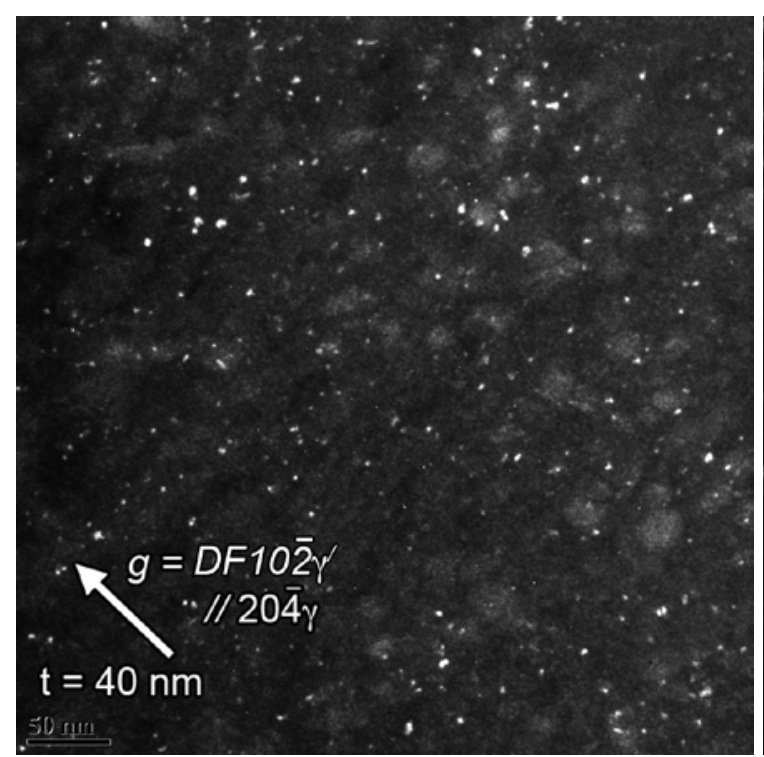

(c)



(b)



(d)

Figure 8. Comparative dark-field images of the $\gamma^{\prime}$ and $\gamma^{\prime \prime}$ phases between the archive material $(\mathrm{a}, \mathrm{b})$ and the irradiated material (c, d). These images are created using specific reflections from the precipitate phases appearing along the $g=240 / 204$ type vectors off the $\gamma[211]$ zone axis (see Figure 7 for indexed zone axis pattern). Partial contrast from the $\gamma^{\prime \prime}$ particles can be seen in the $\gamma^{\prime}$ images (a, c) due to coincidence of $\gamma^{\prime \prime}$ reflections, but the imaging intensity is reduced due to being from weaker $+2 g \gamma^{\prime \prime}$ reflections. Sample thickness (t) affects the perceived particle density. The thicknesses of the samples from which the images were taken were 40 and $84 \mathrm{~nm}$. Localized variations in the crystalline orientation relative to the overall beam direction (i.e., bend contours that change the diffraction deviation parameter) produce some local regions that appear to be lean in particle distribution but are not. 
The dark-field images were used to compare the $\gamma^{\prime \prime}$ phase size between the irradiated and control material. This was a more accurate measurement than that taken using the $\gamma[100]$ zone axis and showed statistically the same average particle size between the nonirradiated and irradiated material (Figure 9). Attempts at an accurate measurement of $\gamma^{\prime}$ were not performed, as any significant change in solute during irradiation would likely be seen in the metastable $\gamma^{\prime \prime}$ particles.

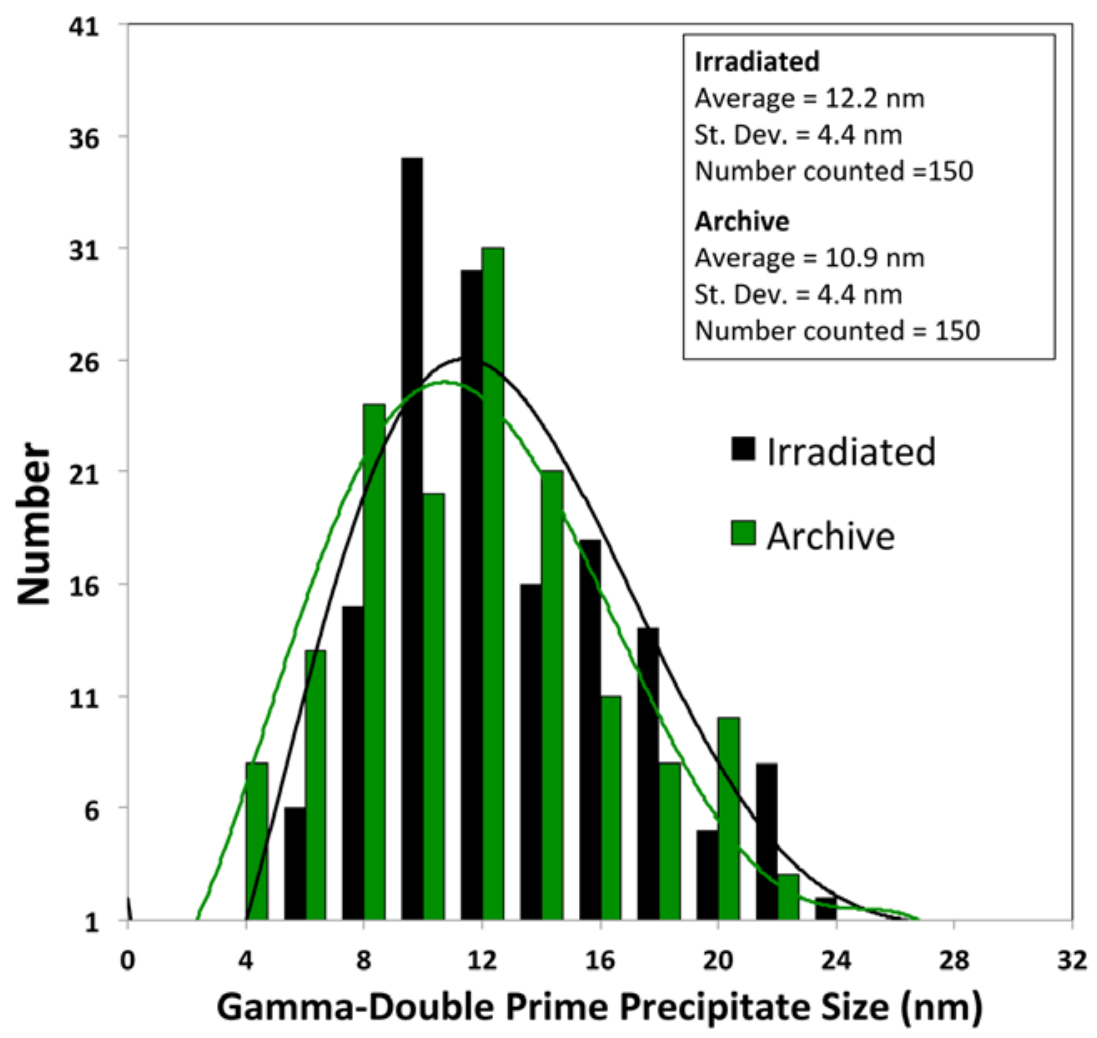

Figure 9. Comparisons of the $\gamma^{\prime \prime}$ precipitate sizes between the irradiated and non-irradiated material from measurements made from dark-field imaging of the $\mathrm{g}=240$ type vector near the $\gamma[211]$ zone axis.

The LS material of this study showed no disordering or radiation-induced dissolution of the precipitate phases for a similar level of displacement damage compared to $3.5 \mathrm{MeV} \mathrm{Fe}^{+}$irradiated alloy 718 data by Hashimoto et al. [14] and $1 \mathrm{MeV} \mathrm{Kr}{ }^{2+}$ irradiated alloy X-750 ( $\gamma^{\prime}$ strengthened alloy) by Zhang et al. [13]. In both literature references, reduction in precipitate reflections (associated with disordering) in electron diffraction patterns along with a visible loss of precipitates were reported following $0.1 \mathrm{dpa}$ or lower for the $\mathrm{Kr}$-irradiated material. The disordering correlates with statistically little reduction in hardness (less than 1\%) up to 1 dpa, with hardness decreasing dramatically with higher doses [14] where particle dissolution occurs. While a $4.7 \%$ loss in hardness was measured for the LS material of this study exposed to $0.14 \mathrm{dpa}$, the lack of measurable change in precipitate ordering and change in volume fraction compared to literature data is indicative of a dose rate effect. Hardness change may be associated with either subtle change in solute distribution as well as the small difference in grain size between the archive and irradiated material. Increasing rates of precipitation dissolution are expected with increasing dose rates and have been reported in electron-irradiated Ni-Si alloy [15], with dose rate dependence more acute at lower temperatures. The ion irradiation studies previously mentioned show exposures of $\sim 10^{-3} \mathrm{dpa} / \mathrm{s}$, while nearly 4 years of time elapsed to achieve the $0.14 \mathrm{dpa}$ in- 
reactor irradiation. Post-irradiation microstructures of alloy 718 exposed to PWR conditions of 2.5, 3.5 and $20 \mathrm{dpa}$ at $288^{\circ} \mathrm{C}$ were reported by Thomas and Bruemmer [16] as showing a loss of $\gamma^{\prime \prime}$ at 2.5 dpa with all $\gamma^{\prime \prime}$ reflections disappearing completely from the electron diffraction patterns by $3.5 \mathrm{dpa}$. In their study, a refinement in size of the $\gamma^{\prime}$ phase was observed up to $20 \mathrm{dpa}$. It is uncertain as to the flux rate. It is interesting to note the presence of $\gamma^{\prime}$ to high dpa, which is not present in the high-flux ion irradiation studies.

As temperature also influences dissolution rate, the $317^{\circ} \mathrm{C}$ nominal temperature of the LS exposure was insufficient to affect a difference compared to that of literature data. In fact, Zhang and coworkers [13] observed that disordering of $\gamma^{\prime}$ in X-750 began at damage levels as low as $0.06 \mathrm{dpa}$ (with dissolution appearing at higher dpa) at temperatures up to $400^{\circ} \mathrm{C}$, but did not occur at $500^{\circ} \mathrm{C}$ and above for tests up to $5.4 \mathrm{dpa}$. The effect of temperature on possible solute segregation effect was further investigated through EDS analysis of the chemistry changes between the archive and irradiated material of the different phases as well as that of the highangle grain boundary compositions. Some of these results are listed in Table 3. The composition data is averaged from at least six measured spectra or more. Errors associated with quantification calculations using ES Vision software for a standardless evaluation are listed along with the standard deviation for an individual atomic species calculated from the multiple spectra measured. The standard deviation provides a comparison of the range of measured values that tend to show a higher variance than that produced from quantification calculation. For $\mathrm{Al}$ and $\mathrm{Si}$, the variance in data is equal to the averaged values.

Table 3. Average measured energy-dispersive spectrometer composition (at. \%) of the $\gamma$ phase taken within the grains (matrix) and at grain boundaries in the archive and irradiated material.

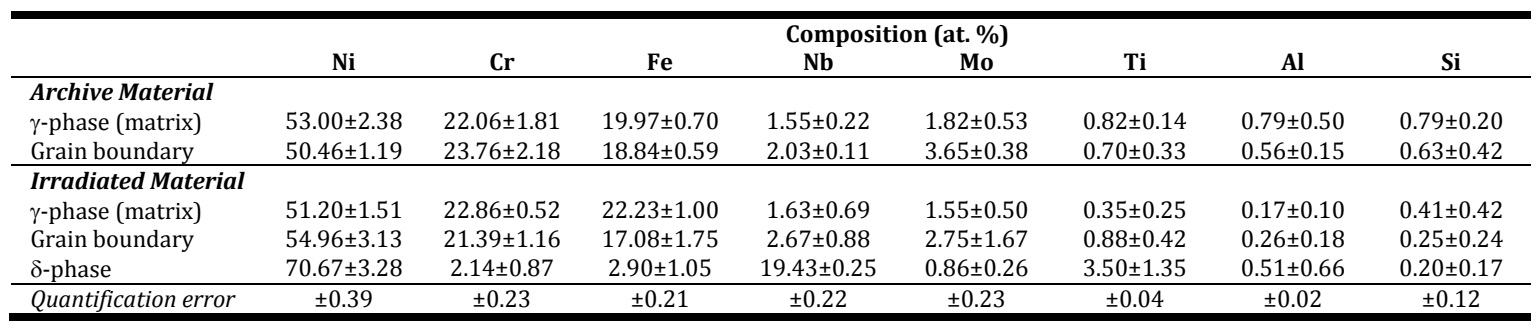

Because the $\gamma^{\prime \prime}$ particles were less than $24 \mathrm{~nm}$ in size and the $\gamma^{\prime}$ particles were even smaller, difficulty in obtaining a clean spectrum of just the precipitate phases made the chemical analysis impractical through TEM. To provide some insurance of data quality, EDS measurements were typically taken from very thin regions of the prepared samples, reducing signal to the spectrometer. However, damage created through sample preparation methods made the thinnest regions of the samples unusable. Even under high-resolution STEM imaging conditions to produce a probe size of 2.4 to $2.6 \mathrm{~nm}$, spectra of the small particles contained contributions from the $\gamma$ matrix. This was evident in the measured compositions near 5 at. \% for Ti and $\mathrm{Al}$ in the $\gamma^{\prime}$ phase, rather than the expected $8 \%$ to $9 \%$ [8, 17-19]. The composition of the $\gamma^{\prime \prime}$ phase was closer to that reported, though the levels of $\mathrm{Ti}$ and $\mathrm{Al}$ varied significantly between the various spectra taken and is likely due to the effect of the varying level of contribution from the matrix phase as well as the reduced peak to background of the spectrum from the precipitate phases. The compositions for the $\gamma^{\prime}$ and $\gamma^{\prime \prime}$ are not provided in Table 3 due to the error associated with measuring very small particles. The most appropriate technique for their accurate measurement is that of atom probe tomography. While this may also be arguable for that of the matrix and grain boundary locations, these locations were more accessible with a relatively higher level of 
confidence. Furthermore, the data in the table are primarily to compare the difference between the data for the archive samples and the irradiated material. The data for the intragranular delta in the archive material was not included, as this phase only appeared at locations in the prepared samples from very thick regions, which produced contributions from the matrix phase.

As follows from Table 3, the grain boundaries show a slightly reduced Fe concentration and slightly increased $\mathrm{Nb}$ and Mo concentrations for both the archive and irradiated material as compared to the matrix $\gamma$ phase. The irradiated LS showed marginally higher Fe in the $\gamma$ phase, and lower $\mathrm{Fe}$ and $\mathrm{Cr}$ values in the grain boundaries as compared to the archive material. The amounts of changes are relatively small and are within the general error range associated with the measured spectrum. This is expected as the nominal irradiation temperature is $<0.3 \mathrm{Tm}$ and therefore is below the range expected for solute redistribution through radiation-induced segregation [20]. This was also evident in the lack of precipitate-free zones near the grain boundaries, which have been reported [21] in alloy 718 following precipitate-hardening treatment at higher temperatures.

Present only as scattered intragranular particles formed early during the processing of the LS material in the archive material, the $\delta-\mathrm{Ni}_{3} \mathrm{Nb}$ phase did start appearing along the high-angle grain boundaries of the irradiated material. However, its appearance was very limited in the small amount of volume associated with the samples that were produced by FIB milling. An example of the development of the $\delta$ phase displaying the strong orientation relationship between it and the parent grain it is growing from is shown in Figure 10. The new $\delta$ phase formation in the irradiated material followed an orientation relationship of $\gamma[110] / / \delta[100], \gamma(\overline{1} 11) / / \delta(010)$ to the parent phase, shown on the left in Figure 10. Growth of the $\delta$ phase precipitates is in the $\delta[002]$ direction from the parent phase. The $\delta$ phase particles appear to create localized curvatures in the grain boundary line as part of the parent grain remains attached to one of the sides of the growing $\delta$ phase. The delta phase composition was determined to contain a few percent $\mathrm{Ti}+\mathrm{Al}$, with lower amount of Mo than that of the surrounding $\gamma$ phase (see Table 3). In general, the composition of the phase was similar to that reported through atom probe and extraction methods $[17,18,22]$. The amount of Mo measured in the $\delta$ phase of this study was lower than the amounts found in other studies, though the composition has been shown to decrease with temperature through Thermocalc evaluations [22]. The presence of $\mathrm{Cr}$ and Fe, were also reported in these other studies $[17,18,22]$, but with higher Fe concentrations. The higher Fe concentrations were also reported for the $\gamma$ phase as compared to this work, which showed Fe level consistently below Cr levels for both the $\gamma$ and $\delta$ phases.

The material in this work also contained carbide inclusion particles visible in the optical micrographs (Figure 2), but more clearly observed through electron microscopy (Figure 11). The particles appear in tight, heterogeneously distributed groupings aligned in the rolling direction of the sheet stock material (rolling prior to annealing and precipitation treatments) despite the material showing no specific grain texturing. The particles were identified through EDS and electron diffraction analysis as the (Nb,Ti)C, cubic $F m \overline{3} m$, phase. An example of the zero order Laue zone (ZOLZ) for the [111] zone axis is provided in Figure 11 (b), which along with other whole pattern and ZOLZ patterns for other zone axis directions (not shown for brevity), distinguished it from the hexagonal and orthorhombic forms of $\mathrm{Nb}_{2} \mathrm{C}$. The $\mathrm{Nb} / \mathrm{Ti}$ ratio was typically near 1.7 for the measured particles. In all of the failed LS material investigated, no evidence was found linking the carbide particles to the source of crack nucleation. 


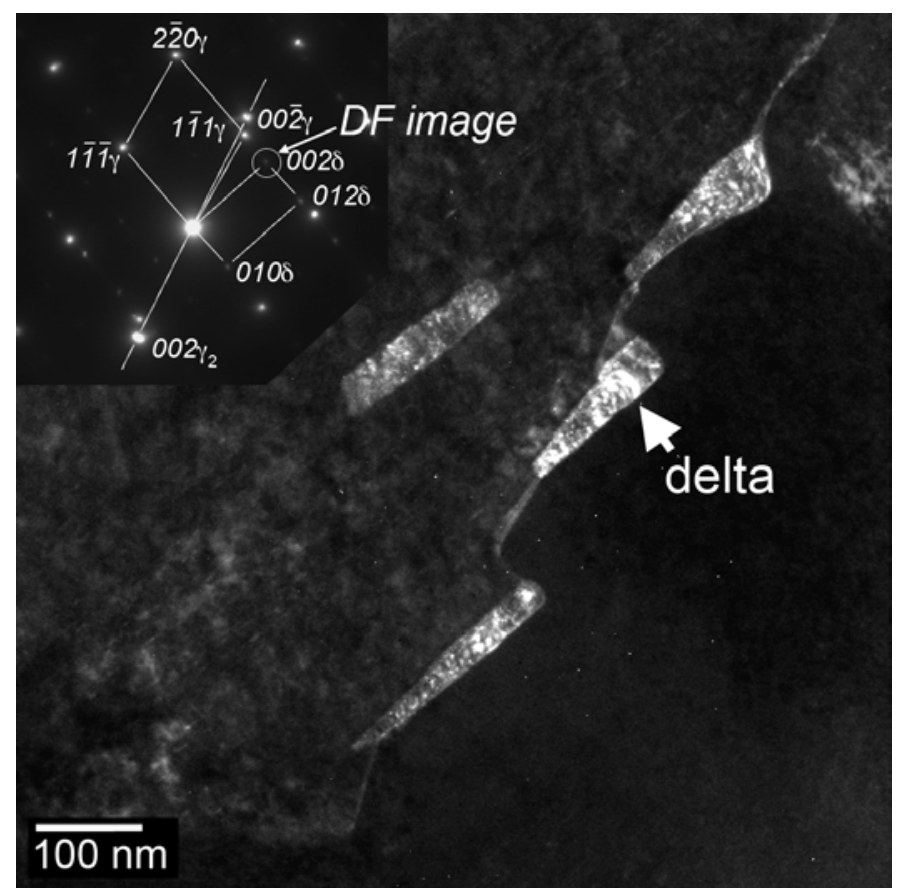

Figure 10. Dark-field micrograph of delta phase precipitation at a high-angle grain boundary in the irradiated leaf spring material, with insert showing the orientation relationship between the precipitate phase and the parent grain (left side of image).

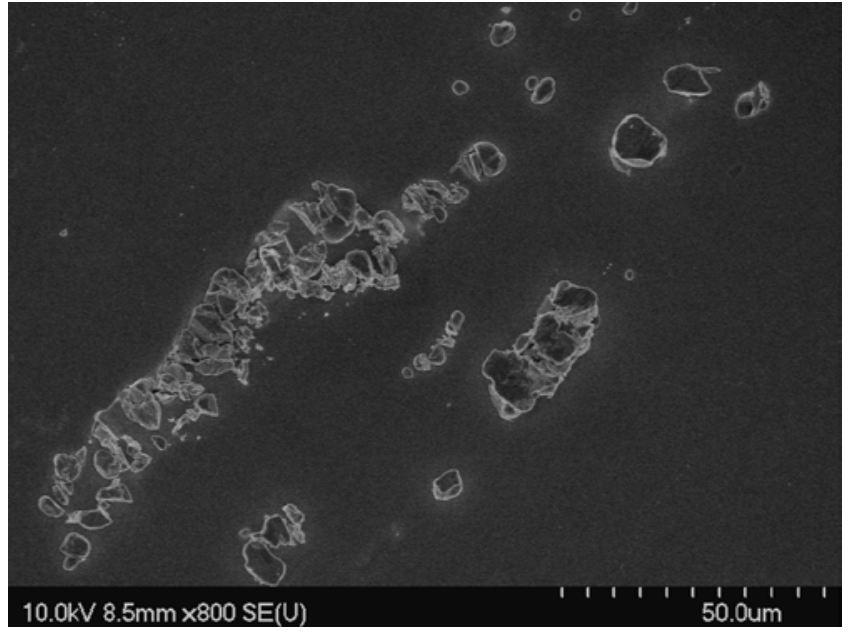

(a)

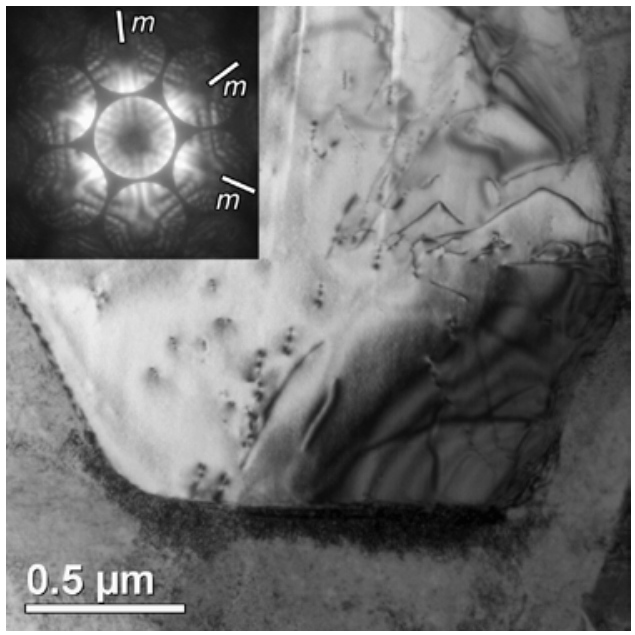

(b)

Figure 11. Example micrographs of the (Nb,Ti)C inclusion particles in the material. (a) SEM image of particles on the surface of an electropolished sample. (b) TEM image of particle, with insert showing the zero order Laue zone image of the [111] zone axis of the cubic $F m \overline{3} m$ structure. Images are from the irradiated material.

\subsection{Crack Propagation Routes and Characterization}

Further examination of the network of cracks in the leaf arm shown in Figure 1, example C, was performed through optical and SEM examination. As shown in Figure 12, the crack network, 
visible on the tensile surface of the LS, shows cracks of different size with occasional changes in direction. For this particular leaf arm, and all similar arms showing little to moderate damage, there were few locations where cracks are significantly wider as compared to the rest that are visible on the surface. For instance, cracks \#1 and \#2 in Figure 12 are wider than the rest and are believed to have initiated first. Dashed white circles mark the areas where cracks grew independently, with weak or no surface interaction with adjacent cracks. When a growing crack enters into a stress field of an adjacent crack, a deviation in its pathway occurs (thin arrows). Analysis of the crack networks across the width of the LS arms suggests multiple crack initiation locations.

Examples of the surface cracks viewed under SEM examination are presented in Figure 13. Close examination of the tensile surface of the sample did not show any direct evidence of crack nucleation from defects such as carbides or secondary phase inclusions. However, much of the wider crack locations had significant oxidized surfaces that could obscure underlying mechanisms. There were also thin fissures in the oxide scale adjacent to cracks that were typically parallel in direction to the crack.



Figure 12. Composite optical macrograph stitched together from multiple images showing crack formations (plane view specimen). Possible crack interactions are represented for few examples, with the widest cracks (\#1, \#2) identified by the thick white arrows as possible nucleation locations. Dashed circles indicate the areas where cracks grew independently with weak or no influence of adjacent cracks. Thin white arrows indicate direction change due to crack stress field interaction. 
The crack pathway in the material was examined through EBSD in both plan-view and crosssection polished specimens of the irradiated material. Figure 14 shows typical crack in the 718 alloy and corresponding EBSD inverse pole figure (IPF) map. The crack propagation path can be easily traced using the corresponding SEM image and/or a local decrease in EBSD image quality (IQ), which produces the thick darkened grain boundaries in the image. It is possible to see that the crack propagated via an intergranular mechanism. No intragranular cracks were observed.



(a)

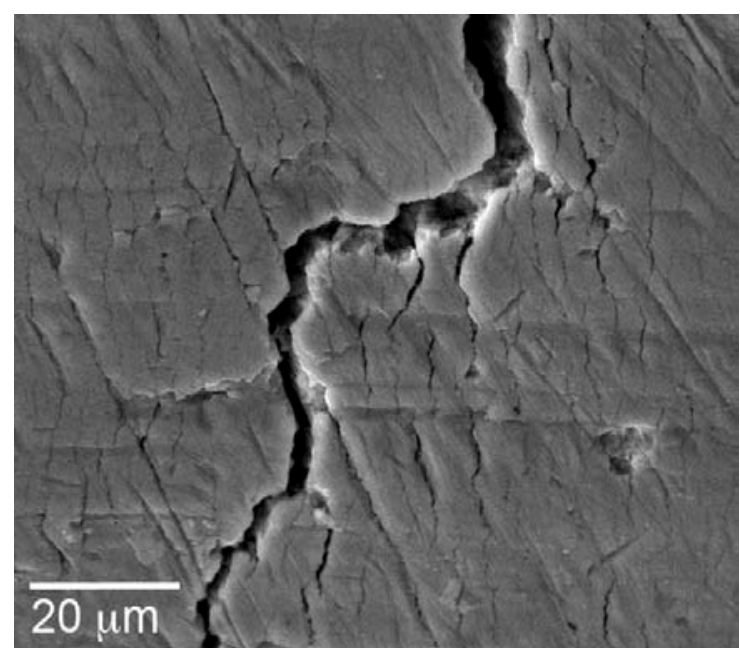

(b)

Figure 13. Scanning electron micrographs of irradiated leaf spring showing (a) crack networks on the tensile surface with terminating cracks near the edge of the leaf arm, and (b) higher magnification of a crack showing breaks in the surface corrosion layer parallel to the crack path.

Grains adjacent to the crack path almost always demonstrated an increased level of in-grain misorientation. This is illustrated in the EBSD grain reference orientation deviation (GROD) maps [Figure 14(c)]. The GROD, sometimes referred as ROD (reference orientation deviation) is one of commonly used EBSD strain metrics [23]. This parameter shows the deviation in orientation of a particular point from the average orientation of the grain. As follows from the image, the GROD value was $\sim 1.5^{\circ}$ to $2^{\circ}$ or more for grains adjacent to the crack, whereas this value did not exceed $\sim 1^{\circ}$ for the noncracked regions of the sample (Figure 14). In some cases, near triple-junction points (TJPs) along the crack route, GROD values often reached $4^{\circ}$ to $5^{\circ}$, which is well above the inaccuracy in the EBSD orientation measurement $\left(\sim 0.5-1^{\circ}\right)$.

As a rule, significant branching was observed at the crack tips; large, well-developed cracks also often had multiple short branches [Figure 14 (a)]. Such branches (or fine secondary cracks) stopped, as a rule, at TJPs; however, few very fine cracks stopped at the middle of the grain boundaries. It may be concluded that that crack moved relatively quickly from one TJP to another ("jumped") with long waiting time between jumps. If a TJP contained at least one random highangle boundary (RHAB), the crack passed it relatively easily. Only TJPs consisting of $\Sigma 3$ s and random low-angle boundaries (RLABs) served as secure crack arrest points. 

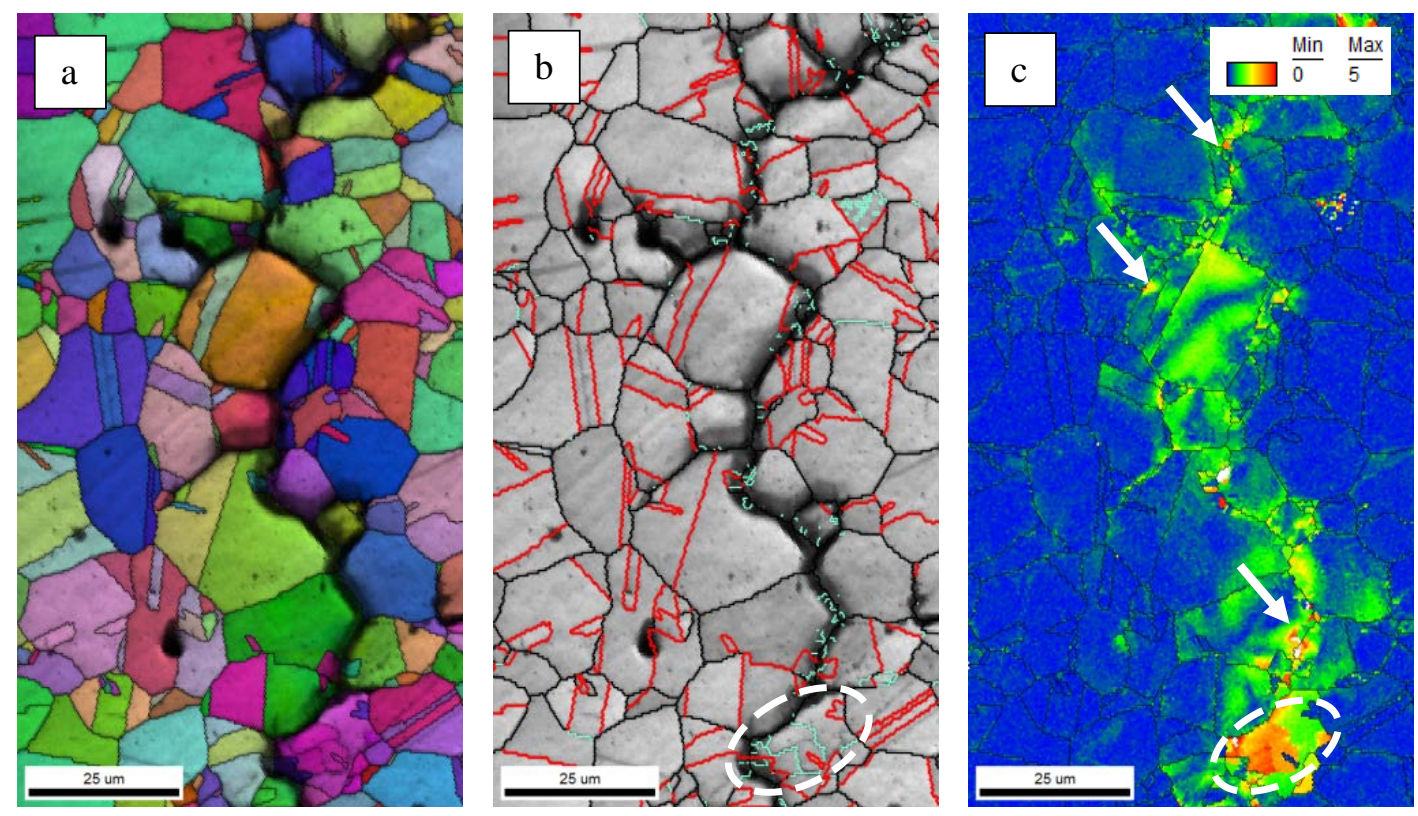

Figure 14. Electron backscatter diffraction analysis maps for large, well-developed crack. (a) [010]-inverse pole figure map showing the orientation of grains; (b) image quality map + grain boundary network map (black: random high-angle boundaries, teal: random low-angle boundaries, and red: $\Sigma 3$-twins); (c) grain reference orientation deviation. White dash oval shows a fragmented grain with multiple low-angle boundaries. Arrows show "hot spots" of localized deformation.

Through analysis of the statistics on cracked and noncracked grain boundaries, it was found that cracks mainly propagated along RHABs. RLABs and twin $\Sigma 3$ boundaries were significantly less involved in cracking. Moreover, all cracked RLABs had the misorientation level more than $10^{\circ}$; no cracked RLABs with $5^{\circ}$ to $10^{\circ}$ misorientation were observed.

Images based on detailed statistics on grain boundary misorientation distribution for the analyzed specimens are shown in Figure 15. As follows from the data, the grain boundary misorientation angle distribution in 718 alloy, in general, is close to the misorientation histogram for a perfect random polycrystal. The strong peak at the $55^{\circ}$ to $60^{\circ}$ range corresponds to the twin boundaries ( $\Sigma 3$ ) formed during annealing. The fraction of twin boundaries is a little higher ( $40 \%$ to $45 \%$ ) than could be expected for a high-nickel alloy (typically around 35\%).

Cracked grain boundary distribution, in general, was very close to the expected theoretical random distribution. However, two exceptions were observed: no cracked boundaries were found for the $5^{\circ}$ to $10^{\circ}$ range, and a fraction of cracked boundaries at the $55^{\circ}$ to $60^{\circ}$ range was significantly less than the fraction in the parent material. Low-angle (RLABs) and twin boundaries are more resistant to SCC compared to RHABs. Grain boundaries other than RLABs and $\Sigma 3$ s cracked with almost the same probability, as they existed in the material investigated.

Also, it was interesting to check if grain orientation relative to the external acting stress influenced cracking. In other words, are the [111]-grains more often involved in cracking compared to the [001]-grains? According to the literature, orientation of the grain to the acting stress strongly influences grain elastic and plastic behavior (Schmid and Taylor factors), and 
recently some authors showed that crack initiation at a particular location depends on the orientation of the adjacent grains. For instance, in irradiated stainless steels, cracks will most likely be initiated at grains with a low Schmid factor (mainly [111]-grains [24]). If a similar rule exists for the crack growth stage, the parameters of parent grain population may be different from the parameters of grains adjacent the crack.

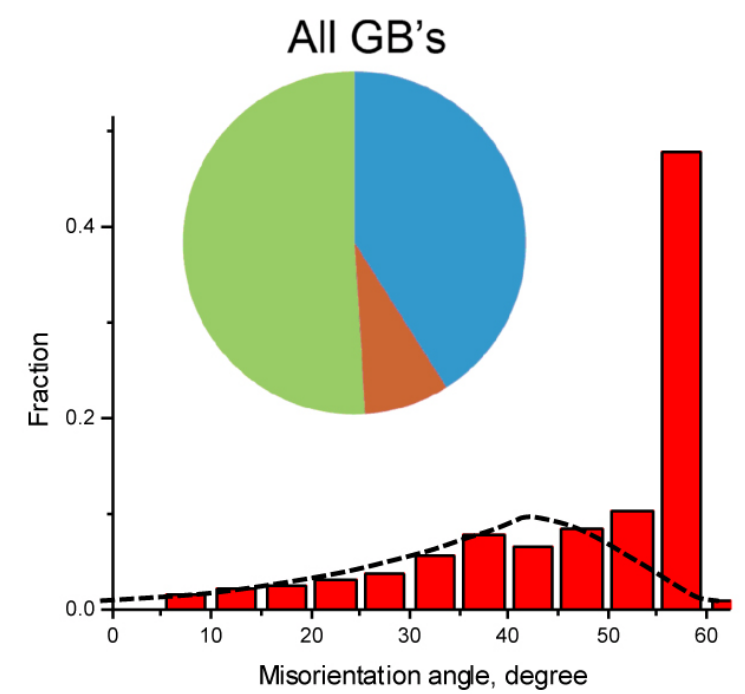

(a)

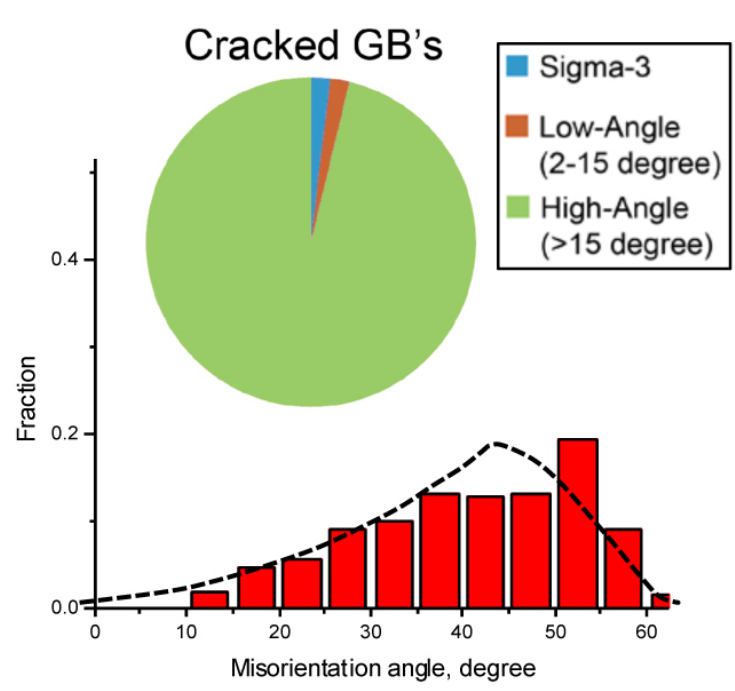

(b)

Figure 15. Distribution of grain boundary misorientation: (a) parent material, far from cracks; (b) cracked grain boundaries reconstructed via EBSD (more than 200 grain boundaries total). Not all grain boundaries with a $60^{\circ}$ misorientation angle were $\Sigma 3$ grain boundaries. Dash line shows theoretical misorientation histogram for a perfect random polycrystal.

A few cracks that developed at the normal direction to the surface were analyzed in detail. Cracks with severe branching were excluded. It was established that there is no pronounced difference between cracked and non-cracked grain populations. As follows from Figure 16, the material away from the cracks contained a slightly increased fraction of [101] grains; however, the texturing was relatively weak (only $\sim 1.45 \times$ random). Grain orientation distribution along the crack path, in general, corresponds to the grain distribution in the volume, far from the cracks. Small differences in the [111]-grain fraction ( 1.05 in the parent material and $\sim 0.9$ at the crack) exist, but this value is too small to be considered meaningful. In the first iteration, it can be concluded that cracks moved in a nonselective manner. It appears that grain orientation relative to an external stress did not influence (or influenced very weakly) crack propagation at the crack growth stage. 


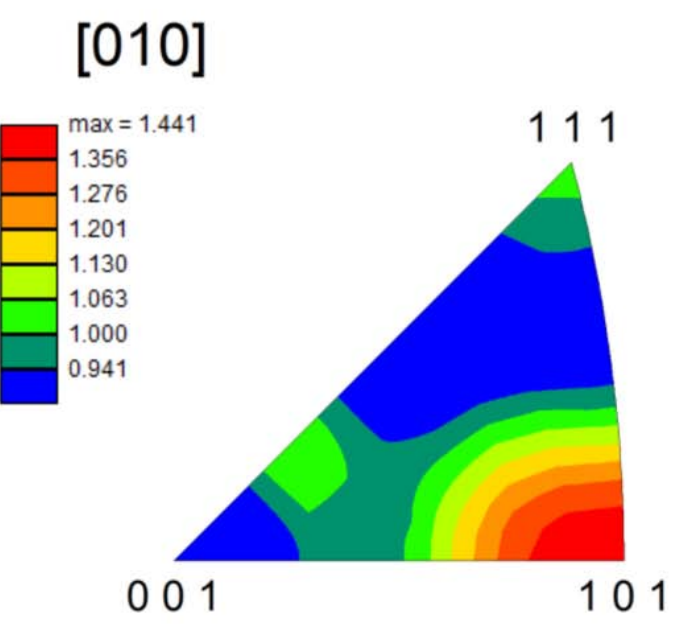

\section{[010]}



Figure 16. [010]-Inverse pole figure texture plot showing orientation of 1600 grains in a noncracked area (left) and orientation of grains adjacent crack path (128 grains total) (right).

During crack path analysis, a number of specific areas were observed and named "plastic bridges." After reaching some particular point, cracks disappeared from the cross-section plane and appeared again after moving out of plane (Figure 17). One or few grain boundaries were able to resist crack propagation, forming a "crack bridging” area. Grains inside the bridge in most cases had significant in-grain misorientation.

The observed plastic bridges formed at specific locations (group of grains of favorable orientation); the conditions and details are not fully clear at the moment. In many analyzed cases, the plastic bridges appeared at TJPs containing few RLAB and $\Sigma 3$ grain boundaries. For instance, there may be a couple of $\Sigma 3$ grain boundaries and RLABs [Figure 17 (a) and (b), point \#3]. Such TJPs were resistant to cracking, and the material inside the bridge experienced some plastic strain to accommodate crack opening. The local increase of misorientation parameters may be severe [Figure 17 (d)], for instance, GROD value may reach $10^{\circ}$ to $15^{\circ}$ [Figure 17 (b)]. 

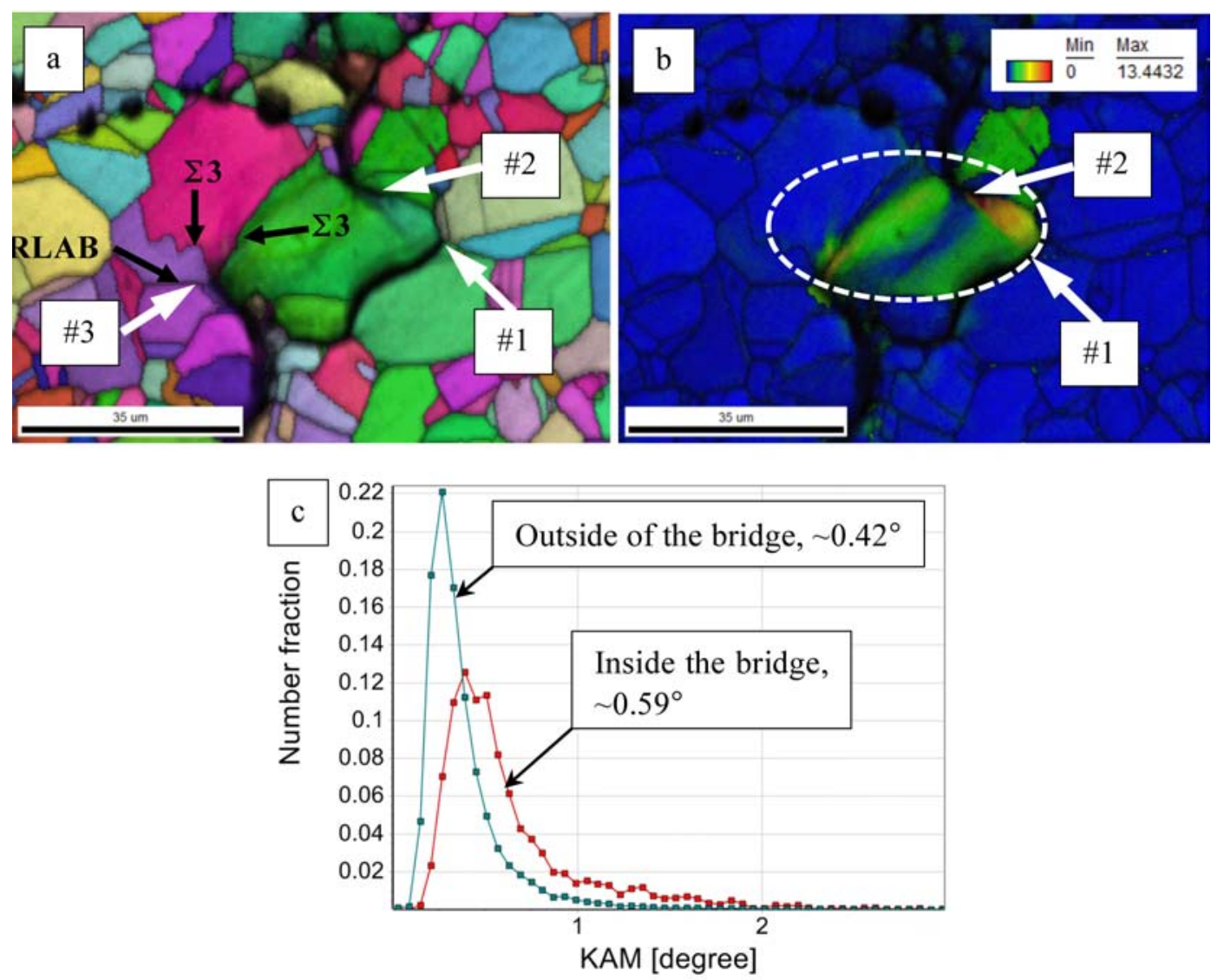

Figure 17. Typical "plastic bridge.” [010]-inverse pole figure + image quality map (a) and grain reference orientation deviation map (b). Crack was not detected in the area shown by white dashed oval. Crack disappeared at point \#1 and appeared again at point \#2. Point \#3 is crack arrest location at a triple-junction point consisting of two $\Sigma 3$ GBs and one RLAB. Kernel average misorientation (KAM) histograms (c) for the out-ofbridge area and crack bridging area [shown by dashed oval in (b)].

\subsection{Detailed TEM Analysis of Near-Crack Regions and Crack Tips}

Specimens for TEM examination of the regions near cracks were prepared through FIB processing. Samples were prepared with FIB lamella at both perpendicular and parallel alignment to cracks. Comparable results were found through both methods, but results from the lift-out perpendicular to the crack provided more information. The location of the sample lift-outs for both orientations was near the crack termination point, as shown in Figure 18(a) for the perpendicular oriented specimen. This was in part an attempt to catch the terminating point but also to minimize the width of the crack relative to the sample being produced in order to maintain structural integrity when thinning to electron transparency. The attempt at catching the terminating end of the crack was partially successful in that it captured smaller cracks not visible on the surface, which followed grain boundaries from the surface but terminated shortly after extending into an initial depth into the material. 




(a)

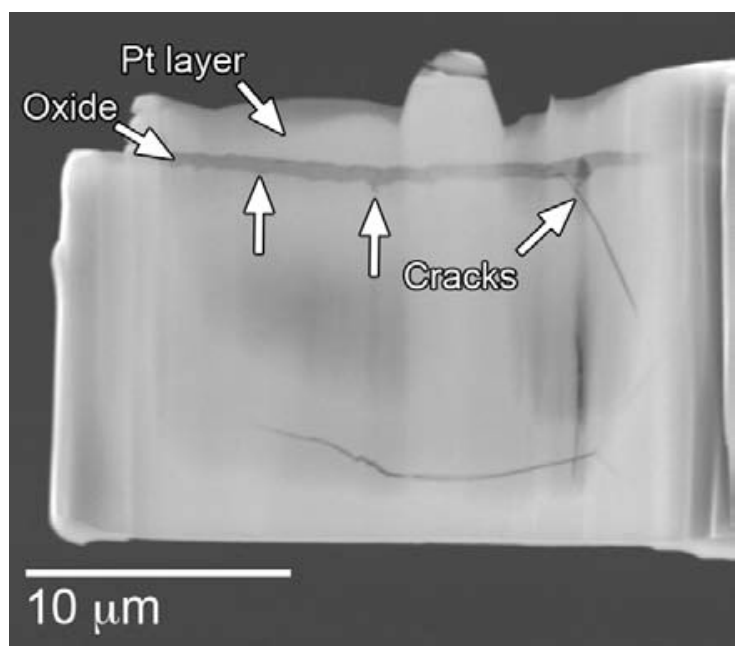

(b)

Figure 18. Secondary electron micrographs taken at different stages of focus-ion-beam (FIB) milling of a specimen extracted perpendicular to a visible surface crack. (a) Lowmagnification view showing the location of the specimen and (b) following extraction and during the process of final thinning. Cracks along grain boundaries, corrosion layer, and deposited-Pt protection layer (from focus ion beam processing) are identified by arrows.

The crack visible in the image of the TEM lift-out specimen [Figure 18(b)] extends along a highangle grain boundary several microns away from the surface. This crack was investigated further through TEM and was found to have oxidized surfaces that are visible in the HAADF image taken under STEM imaging of the sample (Figure 19). Similar to that observed in the polished cross-section image (Figure 3), a change in the height of the grains at the surface of the sample across the cracked grain boundary appears. The stress applied to the LS is in the vertical direction relative to the images in Figure 19, Figure 20, and Figure 21. Slip lines were visible in the material near the crack in directions near orthogonal to the crack as well as micro-twinning in the region where the cracked grain boundary intercepts the surface of the material. Micro-twinning was also observed in other locations but only associated with high deformation areas at the LS surface where cracks had formed.

The cracked areas were examined by TEM and more extensively by SEM during site location for FIB milling and showed no evidence of $(\mathrm{Nb}, \mathrm{Ti}) \mathrm{C}$ or other inclusion particles. This observation, along with the high level of deformation in the near-surface grains, in both the form of slip lines (to be discussed later) and localized twinning, suggests that high localized strain at the grain boundaries is a potential source for crack nucleation.

Examination of the crack in Figure 19 showed oxidation on the crack surfaces. While the appearance of particulate matter as well as a higher $\mathrm{Nb}$ content was found along the edge of the crack, evidence of $\delta$ phase formation was not apparent. The higher $\mathrm{Nb}$ concentration near the crack surface was a common feature of not just the cracked surfaces but also near the free metal surfaces undergoing corrosion. The particulate matter along the crack is composed of oxides similar to those near the free surface of the LS. 




Figure 19. High-angle annular dark-field image of a crack along a high-angle grain boundary. Oxidation of the boundary is evident in the image as the darker area near the grain boundary crack. Also present is micro-twinning visible in bright-field (BF) image (lower insert).

Another crack within the same prepared TEM sample is shown in Figure 20 as extending along a former grain boundary, then diverting into one of the grain interiors, after which it is blunted. The classification of that boundary (high angle versus low angle) is unknown due to the extensive oxidation of the metal in the region. The deviated crack terminates quickly, with the surrounding material significantly oxidized. However, the pathway of the crack in the grain follows along the slip band direction in that particular grain and may be the after-effect of slip band oxidation (i.e., oxidation that occurs when cracks penetrate either the free surface or an oxidized/cracked grain boundary). A small crack along a grain boundary is also observed in Figure 20, but it terminates prior to creating any substantial damage. It is uncertain why this crack was much smaller compared to the others observed on this sample.

The $\delta$ phase that developed along the grain boundary shown in Figure 10, was adjacent to a small surface-penetrating crack and is shown in further detail in Figure 21. The small crack was observed to penetrate into the base metal following a grain boundary as it curves away from the surface. An additional micrograph of the crack tip taken under HAADF imaging under STEM mode is also shown in Figure 21. The grain boundary near the tensile surface (the tensile direction in Figure 21 is in the vertical direction) has been consumed by the growing oxide corrosion surface of the metal. The crack penetrates into the base metal but does not reach the $\delta$ phase precipitates further along the grain boundary. Therefore, it is unknown how the crack will interact with the $\delta$ phase. As the $\delta$ phase at this location produces a locally contorted grain boundary line, some amount of interference with the crack tip would be expected. It is uncertain whether the crack terminated prior to reaching the delta phase due to the changing direction of the 
grain boundary, resulting in a lower stress condition at the tip. The beneficial presence of crack deflections around grain-boundary delta particles and the arrest of crack propagation events during hold times was observed by Viskari et al. [25] in Allvac 718-Plus that was cyclic-fatiguetested at $10 \mathrm{~Hz}$ and $\sigma_{0}=167 \mathrm{MPa}, \mathrm{R}=0.05$.



Figure 20. High-angle annular dark-field image showing a crack developed near the surface that has deflected along the direction of the slip bands in the underlying grain. Extensive oxidation near the crack is visible in the image. Inset: A dark-field image of the slip bands developed in the underlying grain, with the position of the crack marked for reference.

The crack tip and fractured surfaces of the grain boundaries in Figure 21 show oxidation that extends well into the sample from the surface, as in the case for the crack shown in Figure 19. The composition near the regions of the cracks and crack-tip locations was evaluated; results are presented in Table 4. The composition along the edge of the fractured grain boundary shown in Figure 19 was also assessed; the results showed an oxidized surface that has penetrated 10 to 20 $\mathrm{nm}$ inward away from the former grain boundary. Along that boundary, the average Nb level appears to have increased several percent higher than the measured average composition along grain boundaries in the irradiated material. However, no indications were found to suggest $\delta$ phase precipitation. The results in Table 4 are the averaged values from multiple spectra taken at locations along either the fractured surface of the grain boundary or ahead of the crack along a grain boundary. These measured compositions should not be taken as the absolute composition, but they can be used as a benchmarks for the general trends of solute changes. They are compared with the measured compositions of the oxide corrosion scale on the surface of the LS. The oxide corrosion layer changes in composition to an Nb-rich and Fe-lean region at the metal/oxide interface. This corrosion layer chemistry and structure will be addressed in a later paper. The tip of the small crack imaged in Figure 21 (b) was accessible and followed along a grain boundary in 
the material. The crack tip showed a significant amount of oxidation, with decreased $\mathrm{Cr}, \mathrm{Fe}$, and $\mathrm{Nb}$ levels. The Nb level is in contradiction to that of the larger crack in Figure 19. However, the $\mathrm{Nb}$ levels are likely to be diminished ahead of the crack in Figure 21b due to the precipitation of $\delta$ along that particular grain boundary.

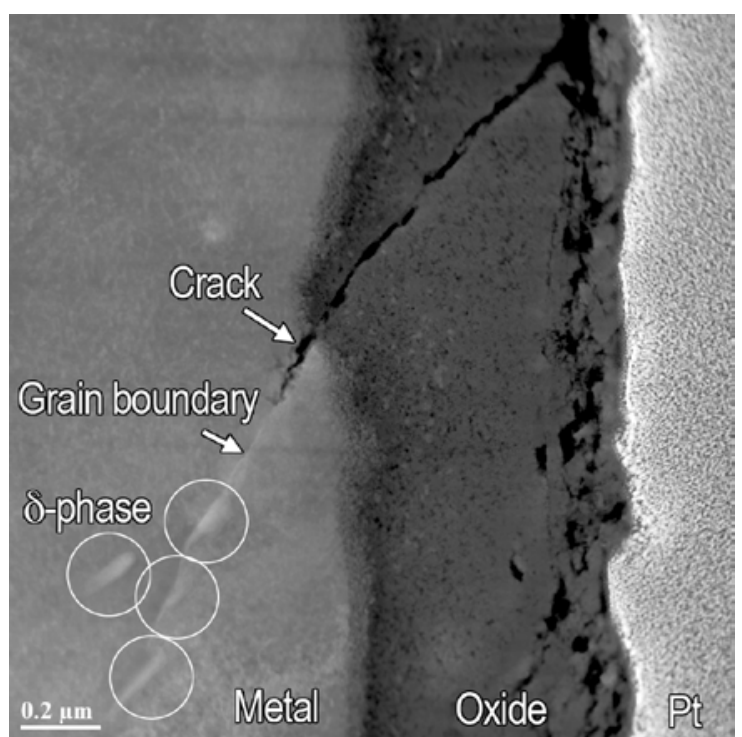

(a)



(b)

Figure 21. Transmission electron microscopy (TEM) micrographs of a small surface originating crack in the irradiated leaf spring. (a) Low-magnification high-angle annular dark-field (HAADF) image taken under scanning TEM conditions showing the intergranular crack penetrating into the base metal but terminating prior to $\delta$ phase particles. (b) Higher-magnification HAADF image of the crack tip, illustrating the dark contrast associated with and qualitatively analyzed as being rich in oxygen.

Table 4. Averaged measured energy-dispersive spectrometer composition (at. \%) taken from multiple spectra at locations associated with cracks or the surface corrosion layer from the referenced images listed. Typical quantification errors are provided, along with the standard deviation in the range of data collected for the spectra analyzed.

\begin{tabular}{|c|c|c|c|c|c|c|c|}
\hline \multicolumn{8}{|c|}{ Composition (at. \%) } \\
\hline Location & $\begin{array}{c}\text { Ref. } \\
\text { Figure }\end{array}$ & $\mathbf{N i}$ & $\mathrm{Cr}$ & $\mathbf{F e}$ & $\mathrm{Nb}$ & Mo & $\mathbf{0}$ \\
\hline Ahead of crack along grain boundary & $21 \mathrm{~b}$ & Bal. & $18.75 \pm 2.25$ & $13.13 \pm 1.85$ & $1.10 \pm 0.58$ & $2.35 \pm 0.54$ & $22.83 \pm 3.63$ \\
\hline Region near cracked grain boundary & 19 & Bal. & $13.68 \pm 2.27$ & $7.93 \pm 0.79$ & $6.34 \pm 0.84$ & $0.99 \pm 0.19$ & $47.16 \pm 4.97$ \\
\hline Oxide layer & 20 & Bal. & $16.29 \pm 2.27$ & $6.77 \pm 0.48$ & $3.19 \pm 1.27$ & $1.29 \pm 0.98$ & $61.39 \pm 4.97$ \\
\hline Quantification error & & - & \pm 0.49 & \pm 0.31 & \pm 0.48 & \pm 0.35 & \pm 0.96 \\
\hline
\end{tabular}

\subsection{Slip Band Characterization and Relation to Cracks}

While the developed corrosion layer on the surface of the LS was nominally about $600 \mathrm{~nm}$, making it thin enough to still show the preexisting tool marks on the surface (none of which correlated to cracks), features possibly relating to the development of conditions near the cracks remain hidden. As SEM examination revealed parallel thin crack formations adjacent to the main 
cracks out to $40 \mu \mathrm{m}$, the penetration depth of those cracks could not be assessed without either cross-sectional techniques or the removal of the oxide surface.

The cleaning was performed using the procedure described in Section 2. After the cleaning, the intergranular cracks became more clearly visible [Figure 22 (a)]. In many cases slip lines were visible on the grain surfaces, both on the surface of the material near the cracks and inside the cracks. However, appearance of the slip lines at the surface was different their appearance inside the cracks; this aspect will be discussed below (section 3.7). In addition to the slip lines, grain boundaries even far from cracks also became visible [Figure 22 (b)], suggesting that a selective grain boundary oxidation took place during the in-reactor service. The oxidation depth and damage associated with grain boundaries were small at less than $1 \mu \mathrm{m}$. The slightly higher $\mathrm{Nb}$ concentration and lower $\mathrm{Cr}$ at the boundaries might cause the selective grain boundary oxidation during irradiation. Another reason might be selective oxygen diffusion along grain boundaries.


Figure 22. (a) Wide, well-developed cracks and fracture surface after chemical cleaning. Tiny secondary cracks are also visible (white arrows); (b) Selective oxidation of grain boundaries and annealing twins (dashed lines) visible following surface oxide removal; (c, d) Examples of secondary cracks observed near the main crack. These secondary cracks (black arrows) are believed to be intragranular.

Ter-Ovanessian et al. [26] investigated alloy 718 exposed to a simulated PWR primary water environment at $360^{\circ} \mathrm{C}$ for $1000 \mathrm{~h}$. The surfaces of the exposed specimens were analyzed using incremental mechanical polishing. It was shown that well-developed intergranular cracks 
presented at the surface; their average depth was $\sim 4 \mu \mathrm{m}$. It was concluded that alloy 718 is not fully immune to intergranular oxidation under PWR conditions. No stress was applied to the specimens, so it is difficult to estimate the ability of the observed cracks to serve as SCC initiation locations. Nevertheless, fine intergranular crack may appear in 718 alloy, even without stress [26].

The most unexpected feature found in the LS material was the appearance of a network of secondary cracks at the surface. Though initially observed in the as-irradiated material through SEM examination of the surfaces [see Figure 13(b)], their depth at the time was undeterminable. Figure 22 (c) and (d) shows examples of a main intergranular crack with numerous secondary cracks adjacent. The secondary cracks, as a rule, were observed only within 20 to $40 \mu \mathrm{m}$ around the main cracks; the density of secondary cracks decreased rapidly as distance to the main crack increased. The depths of the secondary cracks were relatively small; in most cases, they did not exceed 2 to $3 \mu \mathrm{m}$, but sometimes the secondary cracking became severe, leading to grain fragmentation.

Thus, in the irradiated 718 alloy, cracking has a complex nature; in the addition to the large intergranular cracks, small cracks formed at the surface along slip lines. Also, cracking coexisted with pronounced plastic deformation.

\subsection{TEM analysis of slip lines}

A common observation under TEM examination of the irradiated LS is the formation of planer slip bands (or sometimes designated as slip lines) produced from the movement of dislocations through the material. These slip bands develop from the movement of dislocations on the $\{111\}$ planes in the $<110>$ direction. The bands contain dislocation tangles that are very difficult to resolve due to their small size and thickness of the TEM specimen. The slip bands form through the glide-assisted breakup of precipitates, analogous to the dislocation channeling effects seen in other irradiated materials. The formation of slip bands suggests a lack of cross-slip due to low stacking fault energy, resulting in inhomogeneous deformation rather than the formation of loosely shaped dislocation line segments. Alternatively, deformation twinning can also occur in materials with low stacking fault energy. Though not generally observed within the grains of the irradiated LS, deformation twins were observed in the regions near the surface at grain boundary intersections that have undergone cracking (see Figure 19). The deformation twins that appear lenticular should not be confused with the commonly observed and much larger annealing twins present within the grains.

Slip bands created from deformation of the LS were observed in the irradiated material, but not in the archival material. The amount of slip bands present in the irradiated material was a function of depth from the surface as well as proximity to the cracked regions of the material. Furthermore, the degree of uniformity in both the length and the number of active $\{111\}$ planes was also dependent on the same parameters. Examples are shown in Figure 23 (a) and (b) for the area of the LS material near the surface, in the high-stress region of the leaf arm, but away $(>1 \mathrm{~mm})$ from any crack formation. In that region, the lengths of the slip bands were between 40 and 60 $\mathrm{nm}$. The number density of the slip bands was much greater closer to the surface of the leaf form than it was further toward the center thickness of the leaf arm [Figure 23(c)]. The slip bands produce additional streaking reflections in the electron diffraction images and are more pronounced in the $\mathrm{g}=200$ and $\mathrm{g}=220$ imaging conditions. Comparative dark-field images are shown in both Figure 23 and Figure 24 using the diffracted beams from the slip bands and the $\gamma^{\prime \prime}$ phase, which show missing or broken $\gamma^{\prime \prime}$ particles at the locations of the slip bands. 




(a)

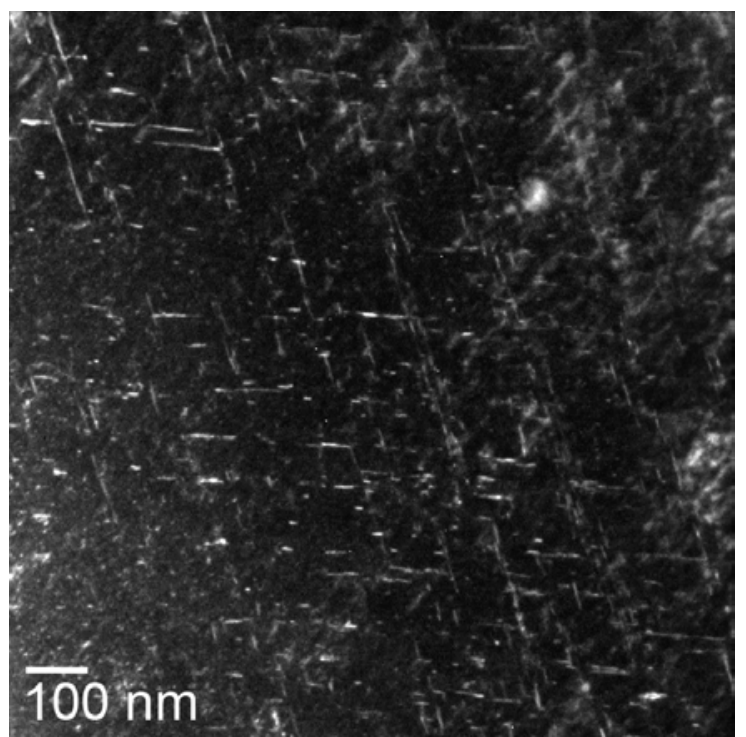

(b)
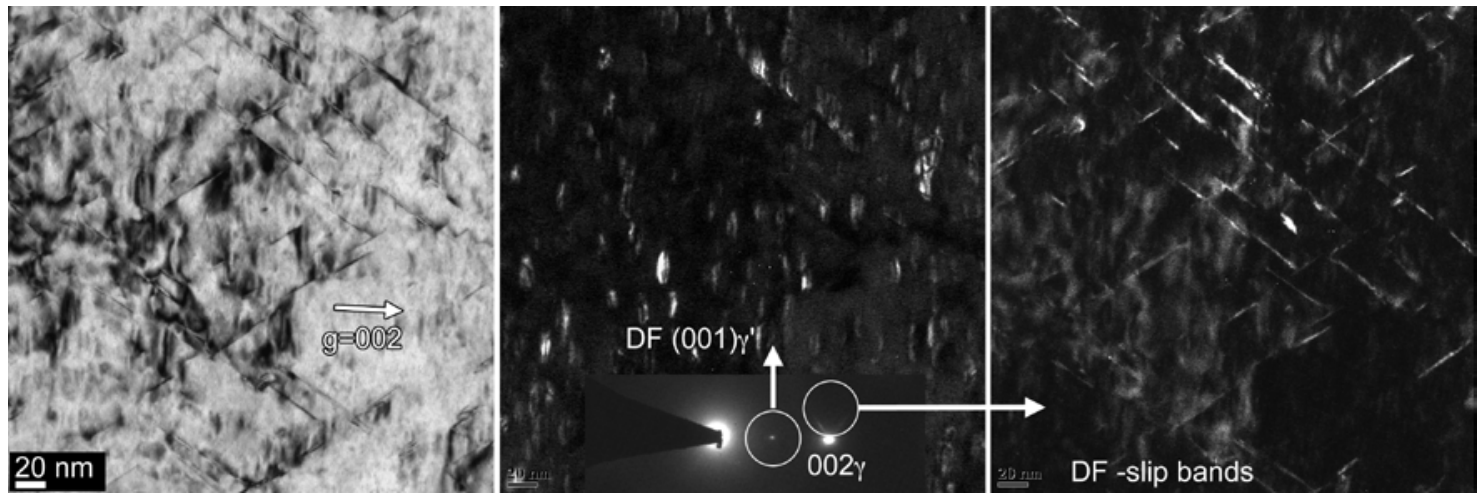

(c)

Figure 23. Examples of slip bands present within the high stress region of the leaf spring but away from any specific crack feature. (a) Bright-field image using the $\mathrm{g}=111$ vector tilted a distance away from the [110] zone axis and (b) dark-field image using reflections from the slip band appearing in the g-vector electron diffraction pattern. (c) Images showing the bright-field and dark-field images of the $\gamma^{\prime \prime}$ and slip bands. The $\gamma^{\prime \prime}$ reflections are missing or show fractures at the locations of the slip bands. Images (a) and (b) were taken relatively near the surface, while images from (c) were taken further away.

The slip bands closer to cracks in the LS are considerably longer (up to several microns) and are unidirectional near the tensile surface of the leaf form (Figure 24). Furthermore, the spacing of the slip bands near the surface is very nonuniform as compared to areas both away from the crack and further into the depth of the material. The lack of slip on multiple planes produces an irregularly strained material. The directionality of the slip bands near the surface may also reflect the nature of the cracking through the depth of the material in that few branches are observed until a significant depth within the material, where the stress, though smaller, may be more uniform. 


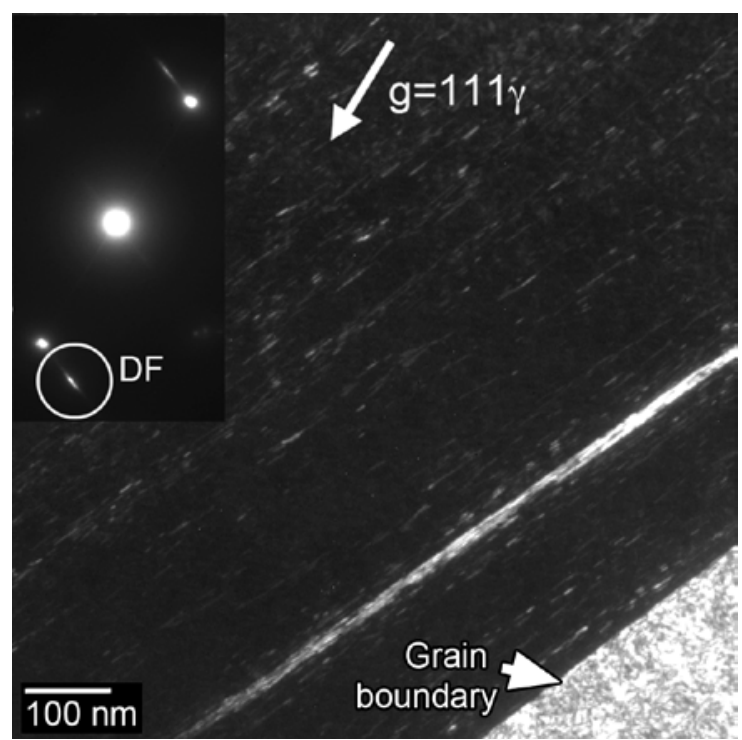

(a)

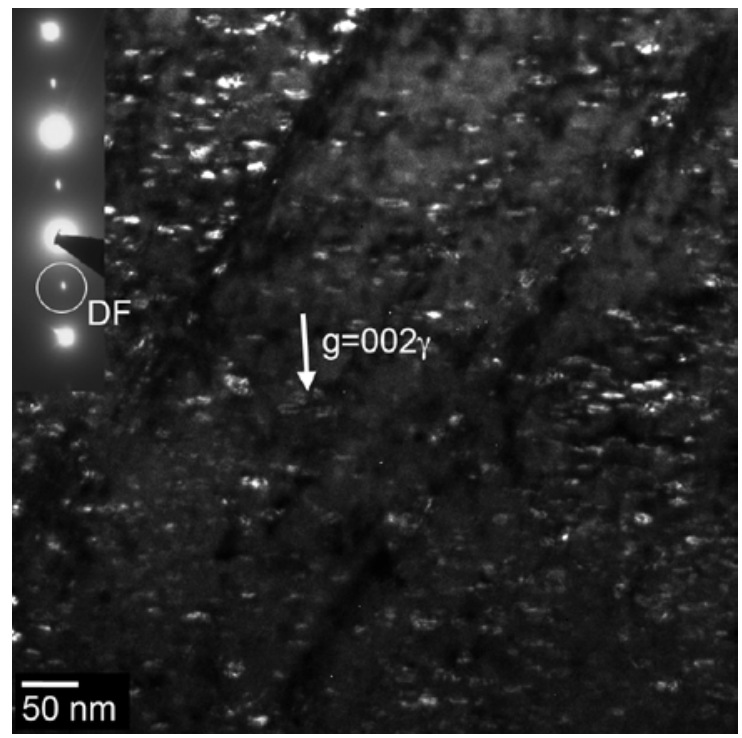

(c)

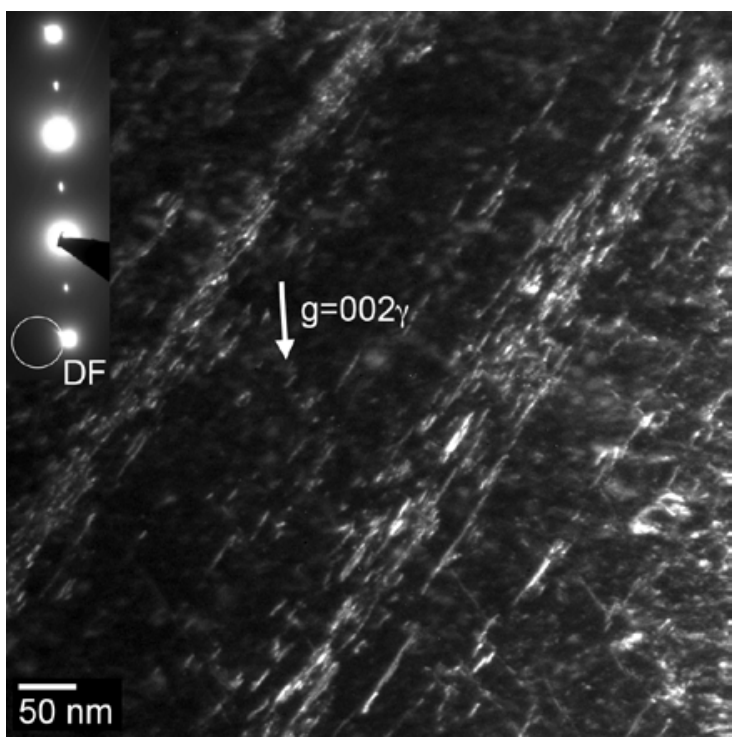

(b)



(d)

Figure 24. Examples of slip bands near cracks in the leaf spring material. (a) Dark-field image, $\mathrm{g}=111$, and (b) $\mathrm{g}=002$ vectors tilted away from the [110] zone axis showing the nonuniform and highly directional deformation occurring near the surface of the sample. Image (c) correlates to that of (b), showing the missing and fractured $\gamma^{\prime \prime}$ particles. (d) Two-beam ( $g=111$ ) bright-field image of defects a further distance into the depth of the leaf spring showing more uniform slip directions.

Analysis of the microstructural data reveals a high density of dislocations near the crack vicinity that has produced the high plastic strain observed in the EBSD evaluation. It is apparent that plastic strain played an important role in cracking because no crack formation was observed in the low-stress regions. Furthermore, the stress loading on the LS during preoperational loading before reactor service places the maximum stress near the base of the leaf arm, above that of the materials yield stress. Therefore, the defect structure near the surface of the LS can have an unintentional effect on SCC. 
The interaction of dislocations with grain boundaries in high-stress regions has been shown in previous research $[27,28]$ to be a source of grain boundary crack initiation. The large number of cracks present through the LS observed in this study suggests that it is also a likely scenario. The high hardness within the grains further increases susceptibility of the material to be unable to yield, which is further exacerbated when oxidation of the grain boundaries occurs. Slip line oxidation may provide further oxygen to into the metal and grain boundaries, but it also has the potential to restrict further deformation along the slip directions, producing a further increased hardening of the material. Oxidation of both the slip lines and grain boundaries was observed and measured through microstructural analysis. Also, there is evidence that the source of crack nucleation points might be the oxidation of both slip lines and grain boundaries.

The oxidation of grain boundaries and slip lines under the high-stress and corrosion conditions of the LS environment produced an unstable situation, in which material could not properly accommodate further strain, resulting in fracturing along grain boundaries. However, the oxidation of those features alone could not account for the failures because they would likely appear in other batches of prepared LS assemblies, which did not produce SCC damage following two-cycle service in PWRs. The reason for this change will be the focus of the next paper on the research that was performed on the alloy 718 LS material.

\section{Conclusions}

A full post-irradiation examination performed on irradiated LS assemblies showed damage following in-service exposure in a PWR. Microstructural and microhardness changes in the material were minimal following exposure, with only a small decrease in measured in material hardness. This was found to be contrary to ion-irradiated material that showed a considerable dose rate effect on both disordering and eventual dissolving of precipitates in the alloy. The low in-service temperatures also resulted in little solute segregation changes in the material. Sources of crack nucleation such as machining defects and (Nb,Ti)C inclusions within the starting material were ruled out due to the locations and characteristics of the cracks.

Analysis of the crack propagation routes established that cracking occurred primarily along highangle grain boundaries; low-angle grain boundaries and twin ( $\Sigma 3$, coincidence site lattice) boundaries were much more resistant to crack propagation. A number of specific areas, which given the name "plastic bridges," were observed along the crack paths; such areas formed when a crack reached a crack-resistant TJP (usually low-angle or twin grain boundaries) and was forced to move out-of-plane.

The grain boundary cracks in the 718 springs showed significant oxidation as well as a high deformation within the nearby grains. Oxidation was also evident along the slip lines intersecting the surface of the LS. The oxidation of the slip lines produce changes to the material's plastic behavior and may have resulted in further oxidation to grain boundary areas at lower depths. The build-up of dislocations at the grain boundaries under the high plastic deformation stresses to which the springs were loaded eventually led to crack initiation at the boundaries to relieve stress. The oxidation of the slip lines and grain boundaries appears to have decreased the material's ability to accommodate deformation. Once initiated, the cracks appear to propagate through an irradiation-assisted SCC mechanism. 


\section{Acknowledgements}

The authors would like to thank Dr. G.O. Ilevbare (EPRI) and Dr. J.L. Nelson (JLN Consulting) for their helpful discussion of the results. This research supported by the U.S. Department of Energy, Office of Nuclear Energy, for the Light Water Reactor Sustainability Research and Development Effort. This manuscript has been authored by the Oak Ridge National Laboratory, managed by UT-Battelle LLC under Contract No. DE-AC05-00OR22725 with the U.S. Department of Energy.

\section{References}

1. AMS Specification 5596J, Nickel Alloy, Corrosion and Heat Resistant, Sheet, Strip, Foil and Plate (52.5Ni-19Cr-3.0Mo-5.1Cb-0.90Ti-0.50Al-18Fe), Consumable Electrode or Vacuum Induction melted 1775F (968C) Solution Heat Treated.

2. T.S. Byun, K. Farrell, J. of Nucl. Mater., 318 (2003) 292-299.

3. $\quad$ L.R. Greenwood, J. of Nucl. Mater. 115 (1983) 137-142.

4. D. Jorge-Badiola, A. Iza-Mendia, I. Gutierrez, Mater. Sci. Eng. A394 (2005) 445-454.

5. D.L. Baty, G.O. Hayner, G.S. Clevinger, and G.L. Garner, "Metallurgical factors affecting the failure of alloy X-750 holddown springs", Proc. of the International Symposium on Environmental Degradation of Materials in Nuclear Power systems - Water Reactors, pub. National Assoc. of Corrosion Eng., Houston, TX (1984) 151-178.

6. J. Chen, G.S. Bauer, T. Broome, F. Carsughi, Y. Dai, S.A. Maloy, M. Roedig, W.F. Sommer and H. Ullmaier, J. of Nucl. Mater. 318 (2003) 56-69.

7. B.H. Sencer, G.M. Bond, F.A. Garner, M.L. Hamilton, S.A. Maloy, W.F. Sommer, J. of Nucl. Mater. 296 (2001) 145-154.

8. M.L. Hamilton, F.A. Garner, M.B. Toloczko, S.A. Maloy, W.F. Sommer, M.R. James, P.D. Ferguson and M.R. Louthan Jr., J. of Nucl. Mater. 283-287 (2000) 418-422.

9. M.R. James, S.A. Maloy, F.D. Gac, W.F. Sommer, J. Chen and H. Ullmaier, J. of Nucl. Mater. 296 (2001) 139-144.

10. F. Carsughi, H. Derz, P. Ferguson, G. Pott, W. Sommer and H. Ullmaier, J. of Nucl. Mater. 264 (1999) 78-88.

11. M.K. Miller, S.S. Babu and M.G. Burke, Mat. Sci. and Eng. A327 (2002) 84-88.

12. J. Deleume, J.-M. Cloué, E. Andrieu, J. of Nucl. Mater. 382 (2008) 70-75.

13. H.K. Zhang, Z. Yao, M.A. Kirk and MR. Daymond, Met. and Matls. Trans. 45A (2014) 3422-3428.

14. N. Hashimoto, J.D. Hunn, T.S. Byun and L.K. Mansur, J. of Nucl. Mater. 318 (2003) 300306.

15. H. Watanabe, T. Muroga, N. Yoshida and K. Kitajima, J. of Nucl. Mater. 158 (1988) 179187.

16. LE. Thomas and S.M. Bruemmer, "Radiation-induced microstructural evolution and phase stability in nickel-base alloy 718", Proc. $8^{\text {th }}$ International Symp. on Environmental Degradation of Materials in Nuclear Power Systems - Water Reactors, Amer. Nuclear Soc., La Grange Park, IL (1997) 772-779.

17. M.G. Burke and M.K. Miller, "Precipitation in alloy 718 a combined AEM and APFIM investigation", in Superalloy 718 and 625 and Various Derivatives, ed. F.A. Loria, Minerals Metals and Materials Soc., Warrendale, PA, (1991) 337-350.

18. M.G. Burke, T.R. Mager and J.L. Nelson, "Stress corrosion cracking of chemistry variants of alloy 718, Part 2: Microstructural Characterization”, Proc. of the Sixth International Symp. on Eviron. Degradation of Matls. In Nuclear Power Systems - Water Reactors, eds. 
R.E. Gold and E.P. Simonen, Minerals Metals and Materials Soc., Warrendale, PA, (1993) 821-827.

19. S.T. Wlodek and R.D. Field, The effects of long time exposure on alloy 718”, in Superalloys 718, 625, 706 and Various Derivatives, ed E. A. Loria, The Minerals, Metals and Materials Society, Warrendale, PA (1994) 659-670.

20. P.R. Okamoto and L.E. Rehn, J. Nucl. Mater. 83 (1979) 2-23.

21. M.G. Burke, T.R. Mager, M.T. Miglin and J.L. Nelson, "The effect of thermal treatment on SCC of alloy 718”, in Superalloys 718, 625, 706 and Various Derivatives, ed E. A. Loria, The Minerals, Metals and Materials Society, Warrendale, PA (1994) 763-773.

22. M.K. Miller and S.S. Babu, "Phase compositions in alloy 718: A comparison between APT/APFIM measurements and thermodynamic predictions", in Advanced Technologies for Superalloy Affordability, eds. K.M. Change et al., Minerals Metals and Materials Society, Warrendale, PA (2000) 63-72.

23. S.I. Wright, M.N. Nowell and D.P. Field, Microscopy and Microanalysis, 17 (2011) 316329..

24. E.A. West, G.S. Was, J. of Nucl. Mater. 408 (2011) 142-152.

25. L. Viskari, Y. Cao, M. Norell, G. Sjöberg, K. Stiller, Mat. Sci. and Eng. A528 (2011) 2570-2580.

26. B. Ter-Ovanessian, J. Deleume, J.-M. Cloué, E. Andrieu, Corrosion Science 67 (2013) 11-19.

27. M.D. McMurty and G.S. Was, "Role of slip behavior in the irradiation assisted stress corrosion cracking in austenitic steels," in 15th International Conference on Environmental Degradation of Materials in Nuclear Power Systems-Water Reactors, John Wiley \& Sons, Inc., Hoboken, New Jersey, Canada (2012) 1383-1394.

28. G.S. Was, "Recent developments in understanding irradiation assisted stress corrosion cracking”, in 11th International Conference on Environmental Degradation of Materials in Nuclear Power Systems-Water Reactors, American Nuclear Society, La Grange Park, IL (2003) 965-985. 